UNIVERSIDADE ESTADUAL PAULISTA “JULIO DE MESQUITA FILHO" FACULDADE DE CIÊNCIAS AGRONÔMICAS

CÂMPUS DE BOTUCATU

\title{
DEFORMAÇÕES ELÁSTICAS E ÁREAS DE CONTATO DE PNEUS AGRÍCOLAS E FLORESTAIS UTILIZANDO PRENSA HIDRÁULICA EM SUPERFÍCIE RÍGIDA
}

EDWARD VICTOR ALEIXO

Dissertação apresentada à Faculdade de Ciências Agronômicas da Unesp Campus de Botucatu, para obtenção do título de Mestre em Agronomia (Energia na Agricultura).

BOTUCATU-SP

Setembro -2015 
UNIVERSIDADE ESTADUAL PAULISTA “JULIO DE MESQUITA FILHO” FACULDADE DE CIÊNCIAS AGRONÔMICAS

CÂMPUS DE BOTUCATU

\section{DEFORMAÇÕES ELÁSTICAS E ÁREAS DE CONTATO DE PNEUS AGRÍCOLAS E FLORESTAIS UTILIZANDO PRENSA HIDRÁULICA EM SUPERFÍCIE RÍGIDA}

\section{EDWARD VICTOR ALEIXO}

Orientador: Prof. Dr. Saulo Philipe Sebastião Guerra

Dissertação apresentada à Faculdade de Ciências Agronômicas da Unesp Campus de Botucatu, para obtenção do título de Mestre em Agronomia (Energia na Agricultura).

BOTUCATU-SP

Setembro -2015 
FICHA CATALOGRÁFICA ELABORADA PELA SEÇÃO TÉCNICA DE AQUISIÇÃO E TRATAMENTO DA INFORMAÇÃO - DIRETORIA TÉCNICA DE BIBLIOTECA E DOCUMENTAÇÃO - UNESP - FCA - LAGEADO - BOTUCATU (SP)

Aleixo, Edward Victor, 1988-
A366d Deformações elásticas e áreas de contato de pneus agrícolas e florestais utilizando prensa hidráulica em superfície rígida / Edward Victor Aleixo - Botucatu : [s.n.], 2015 ix, $52 \mathrm{f}$. : fots. color.; grafs. color., ils. color., tabs.

Dissertação (Mestrado) - Universidade Estadual Paulista, Faculdade de Ciências Agronômicas, Botucatu, 2015 Orientador: Saulo Philipe Sebastião Guerra Inclui bibliografia

1. Pneus agrícolas e florestais. 2. Cargas radiais. 3. Área de contato. 4. Deformação elástica. 5. Pressão de inflação. I. Guerra, Saulo Philipe Sebastião. II. Universidade Estadual Paulista "Júlio de Mesquita Filho" (Câmpus de Botucatu). Faculdade de Ciências Agronômicas. III. Título. 


\section{CERTIFICADO DE APROVAÇÃO}

TíTULO: DEFORMAÇÕES ELÁSTICAS E ÁREAS DE CONTATO DE PNEUS AGRÍCOLAS E FLORESTAIS UTILIZANDO PRENSA HIDRÁULICA EM SUPERFÍCIE RIGIIDA

\section{AUTOR: EDWARD VICTOR ALEIXO}

ORIENTADOR: Prof. Dr. SAULO PHILIPE SEBASTIÃO GUERRA

Aprovado como parte das exigências para obtenção do Título de MESTRE EM AGRONOMIA (ENERGIA NA AGRICULTURA), pela Comissão Examinadora:

Prof. Dr. SAULO PHILIPE SEBASTIÃO GUERRA

Dep de Economia, Sociologia e Tecnologia / Faculdade de Ciencias Agronomicas de Botucatu

Prof. Dr. KLEBER PEREIRA LANÇAS

Dep de Engenharia Rural / Faculdade de Ciencias Agronomicas de Botucatu

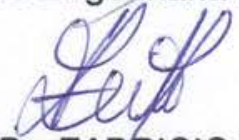

Prof. Dr. FABRICIO LEITE

Departamento de Ciências Agronômicas / Universidade Estadual de Maringa

Data da realização: 17 de agosto de 2015 . 


\section{AGRADEÇO}

À DEUS, pela saúde e pela vida.

\section{DEDICO}

Aos meus queridos pais, Edward e Ivani

À minha amada noiva Amanda

À minha irmã Talita

Pelo carinho, atenção, paciência e incentivo para a conclusão desse trabalho

\section{OFEREÇO}

Aos meus avós paternos, Antonio (in memorian) e Antonia (in memorian) 


\section{AGRADECIMENTOS}

À Faculdade de Ciências Agronômicas (FCA-UNESP), Câmpus de Botucatu e a Coordenadoria do Programa de Pós-Graduação em Agronomia, área de concentração em Energia na Agricultura, pela oportunidade concedida, atenção e ajuda durante o curso de Mestrado, em especial aos Professores Doutores: Adriano Wagner Ballarin e Zacarias Xavier de Barros, coordenadores do programa Energia na Agricultura.

Ao Professor Doutor Saulo Philipe Sebastião Guerra, pela orientação firme e correta, dedicação, atenção e compreensão ao decorrer do curso.

Ao Professor Doutor Kleber Pereira Lanças, pelas sugestões, apoio e amizade.

Ao Professor Doutor Fabrício Leite, pela consideração, conselhos e incentivos à minha carreira profissional.

Ao meu colega e Mestre Pedro Brito, pela ajuda, colaboração e sugestões nas fases do trabalho.

Aos amigos do curso de Pós-Graduação em Energia na Agricultura: João Vitor Testa, Diego Fiorese, Lucas Doimo, Marcelo Denadai, Guilherme Oguri, Indiamara Marasca e Murilo Battistuzzi e pela ajuda e companheirismo.

Aos amigos do NEMPA: Emanuel Spadim, Luiz Balestrin, Miguel Pascucci, Fellipe Damasceno, Thiago Ramos e Romulo Leonardo pela atenção dedicada durante esses anos.

Aos amigos e colegas de república: João Vitor Testa, Diego Fiorese, Tiago Zoz e Ismael Fernandes pelo crescimento pessoal e convivência.

À Trelleborg Wheel Systems pelo fornecimento do pneu para realização dos ensaios. 
Aos funcionários da Trelleborg Wheel Systems, José Artioli, Mauro Oliveira e Elídio Miralha pela amizade, apoio e incentivo durante o período do curso.

Às secretárias da seção de Pós-graduação da FCA-UNESP, Campus de Botucatu, pelo atendimento e atenção.

A todas as pessoas e instituições que contribuíram para a realização deste trabalho. 


\section{SUMÁRIO}

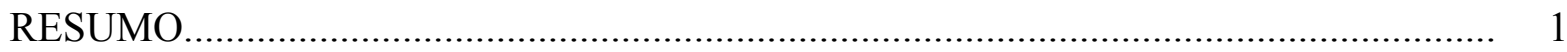

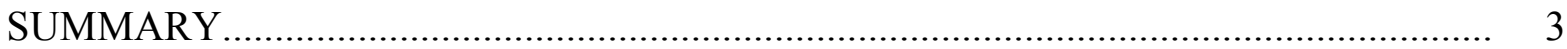

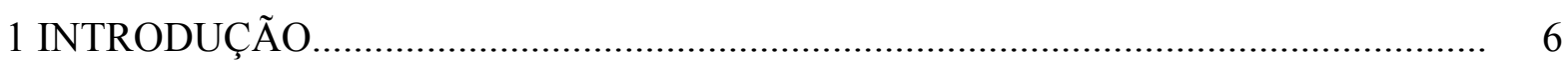

2 REVISÃO BIBLIOGRÁFICA..................................................................................... 7

2.1 Histórico dos pneus e rodados........................................................................... 7

2.2 Histórico dos pneus agrícolas............................................................................ 8

2.3 Produção e mercado de pneus................................................................................... 9

2.4 Importância do pneu nas máquinas agrícolas e florestais........................................ 11

2.5 Características dos pneus................................................................................... 11

2.6 Tipos construtivos de pneus......................................................................... 14

2.7 Pneus agrícolas e florestais............................................................................. 15

2.8 Pressão de inflação............................................................................................. 17

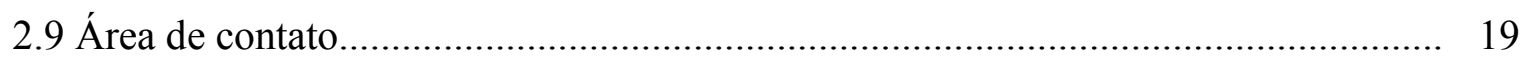

2.10 Deslocamentos laterais do pneu.................................................................... 20

2.11 Compactação do solo..................................................................................... 22

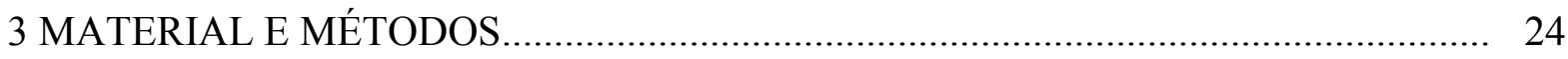

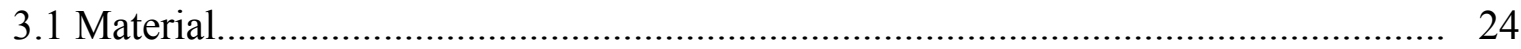

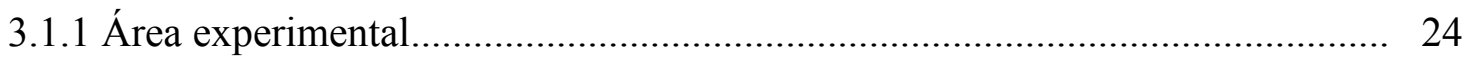

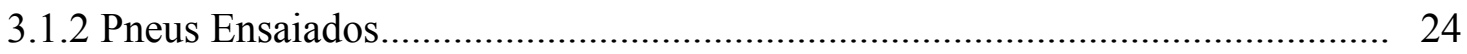

3.1.3 Prensa hidráulica e superfície rígida........................................................... 26

3.1.4 Sensores de deslocamento..................................................................... 27

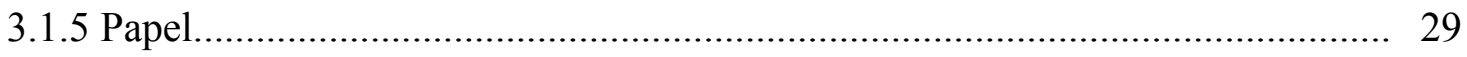

3.1.6 Manômetro de aferição de pressão dos pneus.................................................... 30

3.1.7 Tinta de carimbo.................................................................................. 30

3.1.8 Câmera fotográfica digital....................................................................... 30

3.1.9 Programas computacionais..................................................................... 30

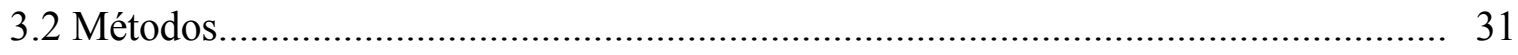

3.2.1 Aplicação de carga nos pneumáticos................................................................ 31 
3.2.2 Impressão da banda de rodagem em uma superfície rígida........................... 32

3.2.3 Obtenção das áreas de contato a partir da impressão................................... 32

3.2.4 Obtenção do deslocamento vertical e horizontal......................................... 32

3.2.5 Pressões de inflação e cargas aplicadas no pneu agrícola e florestal................. 33

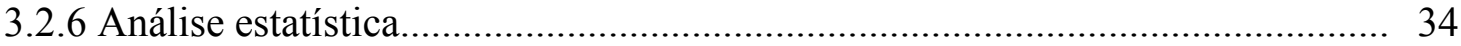

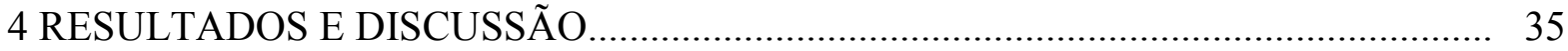

4.1 Deslocamento vertical do pneu agrícola e florestal............................................ 36

4.2 Deslocamento horizontal do pneu agrícola e florestal........................................ 38

4.3 Área de contato do pneu agrícola e florestal.................................................. 40

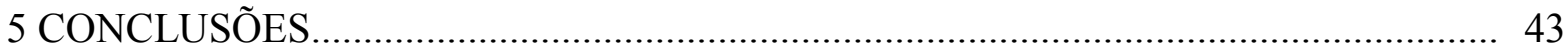

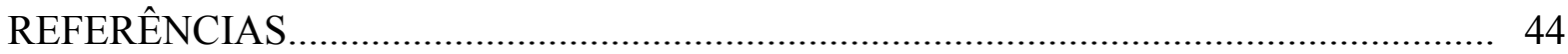




\section{LISTA DE FIGURAS}

Figura 1. Porcentagem da participação de cada segmento na venda global de pneus...............10

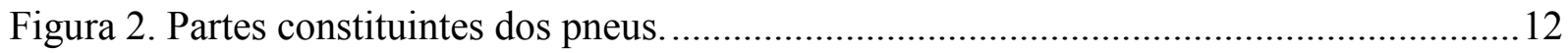

Figura 3. Pneu Diagonal (A), BPAF (B) e Radial (C)................................................... 15

Figura 4. Princípios construtivos dos pneus florestais. ..................................................... 16

Figura 5. Deslocamento vertical e horizontal do pneu com aplicação de carga.......................22

Figura 6. A: Pneu agrícola; B: Pneu florestal.................................................................26

Figura 7. Prensa hidráulica e superfície rígida utilizada no ensaio de pneus. .........................27

Figura 8. Potenciômetro da marca Kyowa, modelo DT 100 A............................................28

Figura 9. Potenciômetro utilizado para coletar o deslocamento horizontal do pneu................28

Figura 10. Potenciômetro utilizado para coletar o deslocamento vertical do pneu..................29

Figura 11. Papel sob a superfície rígida com escala.........................................................29

Figura 12. Dados do ensaio do pneus apresentados no monitor da prensa .............................31 


\section{LISTA DE TABELAS}

Tabela 1. Os dez maiores fabricantes de pneus e as vendas de pneus nos anos 2012 e 2013 no

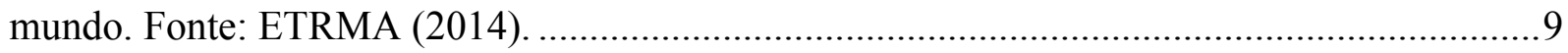

Tabela 2. Produção de unidades de pneus por categoria no Brasil, segundo ANIP (2013)......10

Tabela 3. Classificação de pneus para implementos e máquinas agrícolas e florestais, de acordo com o tipo de desenho da banda de rodagem. Fonte: ALAPA (2013).

Tabela 4. Características técnicas do pneu agrícola e florestal utilizado no ensaio em superfície

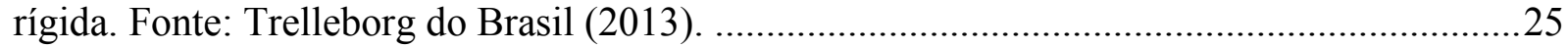

Tabela 5. Pressões de inflação recomendadas, segundo o fabricante, de acordo com a carga aplicada sobre o pneu agrícola. Fonte: Trelleborg (2015).

Tabela 6. Pressões de inflação recomendadas, segundo o fabricante, de acordo com a carga aplicada sobre o pneu florestal. Fonte: Trelleborg (2015)

Tabela 7. Resumo da análise de variância para a variável deslocamento vertical, deslocamento

horizontal e área de contato. 35

Tabela 8. Valores médios de deslocamento vertical do pneu agrícola e florestal...................38

Tabela 9. Valores médios de deslocamento horizontal do pneu agrícola e florestal................39

Tabela 10. Valores médios da área de contato do pneu agrícola e florestal............................41 


\section{RESUMO}

Os pneus agrícolas e florestais interferem significativamente no desempenho e rendimento das máquinas, sendo relevante o conhecimento de suas estruturas, pois existe uma íntima ligação do equipamento com o solo, e estes são responsáveis pela sustentação, propulsão e direcionamento das máquinas. Diversas características do pneu como a pressão de inflação, área de contato e a disposição e altura das garras na banda de rodagem interferem na física do solo. O presente trabalho tem como objetivo avaliar a área de contato e os deslocamentos vertical e horizontal de dois pneus BPAF (Baixa Pressão e Alta Flutuação), um agrícola e um florestal, com as mesmas dimensões 600/55-26.5, em superfície rígida, em função da aplicação de diferentes pressões de inflação, segundo a orientação do manual técnico do fabricante, e a submissão dos mesmos a cargas suportadas. Foi utilizada uma prensa hidráulica pertencente ao NEMPA (Núcleo de Ensaio de Máquinas e Pneus Agroflorestais) da Faculdade de Ciências Agronômicas - UNESP, Câmpus de Botucatu - SP. O pneu agrícola foi submetido aos seguintes tratamentos de pressões e cargas: 48,2 kPa e 25 kN, $193 \mathrm{kPa}$ e $50 \mathrm{kN}$, $234,4 \mathrm{kPa}$ e $50 \mathrm{kN}, 344,7 \mathrm{kPa}$ e $50 \mathrm{kN}$. No pneu florestal foram realizados os tratamentos de pressões e cargas: $158,5 \mathrm{kPa}$ e $35 \mathrm{kN}, 241,3 \mathrm{kPa}$ e $50 \mathrm{kN}, 379,2 \mathrm{kPa}$ e $50 \mathrm{kN}$ e 496,4 kPa e 50 kN. Fixou-se uma folha de papel à uma superfície rígida para obtenção das áreas de contato dos pneus, e os mesmos foram prensados sobre a folha anteriormente citada. Secundariamente, foi posicionada uma fita de papel milimétrico. Foram obtidas fotos de cada área de contato e as leituras das áreas de contato foram realizadas utilizando o software ImageJ. Para obtenção dos valores dos deslocamentos horizontal e vertical utilizou-se dois sensores do tipo potenciômetros lineares. Observou-se que, com o aumento da pressão de inflação, o pneu agrícola apresentou menor deslocamento vertical, horizontal e área de contato, ocorrendo o mesmo com o pneu florestal. Por sua vez, quando mensurado o deslocamento vertical, o pneu agrícola apresentou valores mais elevados quando comparado ao pneu florestal. No deslocamento horizontal, o pneu agrícola apresentou menor valor em relação ao florestal, e, não houve diferença entre os dois pneus em relação a pressão mínima. Considerando-se a área de contato, quando eleva-se a pressão de inflação, há redução da mesma nos dois pneus. A pressão de inflação influenciou nos parâmetros avaliados para os pneus agrícola e florestal, sendo o pneu agrícola o mais sensível ao aumento da pressão de inflação. Conclui-se que alta pressão de inflação torna o pneu mais 
rígido, reduzindo sua área de contato com a superfície, e desta forma, o pneu agrícola assemelhase ao florestal quando submetido à alta pressão de inflação, uma vez que ambos os pneus apresentaram os mesmos resultados.

Palavras-chave: pneus, carga do pneu, deformação do pneu, pressão de inflação. 
ELASTIC DEFORMATIONS AND CONTACT AREAS OF AGRICULTURAL AND FORESTRY TIRES USING A HYDRAULIC PRESS IN HARD SURFACE. Botucatu, 2015, 52p. Dissertação (Mestrado em Agronomia/Energia na Agricultura) - Faculdade de Ciências Agronômicas, Universidade Estadual Paulista.

Author: EDWARD VICTOR ALEIXO

Adviser: SAULO PHILIPE SEBASTIÃO GUERRA

\section{SUMMARY}

Agriculture and forestry tires influence significantly the machines efficiency, thus it is relevant to consider their structures, because there is a directly relation between tires, that are responsible for the support, propulsion and steering of machines, and soil. There are several tires characteristics that impact soil physics, like inflation pressure, contact area, and the height of tread claws. The present study had as objective to evaluate the contact area, vertical and horizontal displacement of two BPAF (low pressure and high fluctuation) tires, one forestry and other agricultural, of same dimensions (600/55-26.5), in rigid surface, by applying different inflation pressures regarding the manufacturer's technical manual, and submitting both tires to supported loads. The experiment was accomplished using a hydraulic press in NEMPA (Agroforestry Machine and Tire Testing Center) located at Faculty of Agricultural Sciences (FCA/UNESP) in Botucatu-SP. The agricultural tire was submitted to the following pressure and loads treatments: 48,2 kPa and $25 \mathrm{kN}, 193 \mathrm{kPa}$ and $50 \mathrm{kN}, 234,4 \mathrm{kPa}$, and $50 \mathrm{kN}, 344,7 \mathrm{kPa}$ and $50 \mathrm{kN}$. While the forestry tire was submitted to pressure and loads treatments as follow: 158,5 kPa and $35 \mathrm{kN}, 241,3 \mathrm{kPa}$ and $50 \mathrm{kN}, 379,2 \mathrm{kPa}$, and $50 \mathrm{kN}$ e 496,4 $\mathrm{kPa}$ and $50 \mathrm{kN}$. To get the contact area of each tire, they were pressed to a paper sheet that was fixed to a rigid surface. Then, a millimetric paper tape was placed. Pictures of each contact area were taken, and the areas were read with the software ImageJ. To obtain the values of horizontal and vertical offsets, two linear potentiometers sensors were used. It was observed that when 
increasing inflation pressure, both forestry and agricultural tires showed less vertical and horizontal displacement, and smaller contact area. In other hand, considering only vertical displacement, the agricultural tire resulted in higher values than the forestry tire. Regarding horizontal displacement, agricultural tires resulted in lower values, and there was no difference between the two tires in relation to a minimum pressure. There was a reduction in contact area of both tyres when increasing inflation pressure. The inflation pressure influenced all parameters evaluated for both tires, being the agricultural the most sensitive to inflation pressure rising. It was concluded that high pressure inflation makes the tire stiffer, reducing its contact area with the surface, and thus, agricultural tires resembles the forestry when subjected to high inflation pressure, since both tires showed the same results.

Keywords: pneumatic wheels, tire load, tire deformation, inflation pressure. 


\section{INTRODUÇÃ̃O}

As máquinas agrícolas e florestais ao longo de décadas foram submetidas a melhorias com objetivo de aumentar a produtividade e a capacidade operacional de trabalho e otimizar o consumo de combustível. Para que isso fosse possível, ocorreu um aumento de massa e tamanho das máquinas, elevação da potência de seus motores, introdução de tecnologias como o GPS, softwares de computadores e mecanismos eletrônicos, sendo que o componente responsável pela locomoção, suporte de massa das máquinas, transmissão da potência da máquina ao solo, imposição da força de tração são os pneus a elas acoplados.

Os pneus agrícolas e florestais passaram por vários processos de modernização de suas estruturas, como a fabricação de pneus que utilizam baixa pressão de inflação e alta flutuação o que minimiza a compactação do solo, utilização de compostos resistentes e ao mesmo tempo flexíveis e o aperfeiçoamento das garras da banda de rodagem para se adaptarem aos diferentes tipos de solo.

Esses tipos de pneus são utilizados em máquinas que operam em diferentes tipos de solos, relevos, climas e temperaturas. Cada um deles apresenta uma série de particularidades tais como, compostos de borracha, disposição das lonas e material que os compõe e, além disso, são montados em diversos modelos de máquinas com dimensões e peso variados. 
O pneu florestal geralmente é montado em máquinas utilizadas em florestas naturais ou plantadas, que realizam plantio, colheita e remoção de madeira. Estes ambientes possuem obstáculos como cepas de árvores cortadas, tocos e outros resíduos, incluindo galhos e folhas. Trabalhando nessas condições, o pneu pode sofrer deformações como perfurações, fissuras e arranque de borracha. Os pneus florestais são fabricados a partir de compostos de borracha resistentes e apresentam cordonéis de aço sob a banda de rodagem, visando a redução de danos. Essas características conferem maior rigidez ao pneu florestal e possibilitam que os mesmos trabalhem com pressão de inflação mais elevada quando comparados aos pneus agrícolas.

Os pneus agrícolas são fabricados com os mesmos parâmetros do pneu florestal, no entanto, os compostos de borracha deste apresentam menor resistência e não possuem cintas de aço sob a banda de rodagem, visto que não trabalham em áreas com resíduos como galhos e tocos de árvores, mas com restos vegetais de culturas que não provocam danos e perfurações ao pneu.

Visando demonstrar a importância das características dos pneus agrícolas e florestais, principalmente àquelas relacionadas ao estudo das diferentes formas de construção dos pneus, e como estas diferenças estruturais podem influenciar o desempenho das máquinas, foi desenvolvida esta pesquisa, com o objetivo de avaliar a área de contato e o deslocamento horizontal e vertical de um pneu agrícola e um florestal, em função das pressões de inflação e aplicação de cargas sobre uma superfície rígida. 


\section{REVISÃO BIBLIOGRÁFICA}

\subsection{Histórico dos pneus e rodados}

Em 1843, Charles Goodyear patenteou o processo de vulcanização da borracha, que a deixaria mais estável e resistente às mudanças de temperatura. Já em 1846, Robert Willian Thomson inventou o pneumático, mas logo abandonou a ideia a favor de tiras de borracha maciça em torno das rodas. Em 1889, Dunlop, por sua vez, iniciou a fabricação dos primeiros aros adaptados a pneus infláveis de bicicleta, ou pneumáticos, como constava da sua patente. Contudo, em 1891, a patente do primeiro pneumático foi reconhecida a Thomson (Márquez, 2010).

Edouard Michelin construiu diversos protótipos de rodas, desenvolvendo então, um pneu desmontável para bicicletas. Em 1895, os irmãos Michelin fabricaram rodas pneumáticas para um automóvel, abrindo o caminho para os pneus na indústria do automóvel (MICHELIN, 2015).

Diante desses fatos, as pesquisas em pneumáticos foram acentuadas com melhorias, tais como o lançamento do pneu diagonal em 1904 pela Goodyear e pela Firestone, utilizando tecidos de algodão dispostos em ângulos cruzados e adição de compostos de petróleo, resultando num composto mais resistente e durável. Em 1923, a Firestone lança o pneu balão 
que possuía uma seção mais larga, perfil mais baixo e pressão de inflação menor, resultando em um maior conforto e maior vida útil ao pneumático (GOODYEAR, 2015; FIRESTONE, 2015).

Em 1934, a Michelin vulcanizou fios de aço na carcaça, gerando pneus extremamente resistentes, pois suportavam um número elevado de cargas. Com a descoberta de fios de aço na carcaça, a empresa Michelin desenvolveu o pneu radial em 1946 implementando no mercado um novo conceito de pneumático, separando as funções entre banda de rodagem e os flancos do pneu (MICHELIN, 2015).

\subsection{Histórico dos pneus agrícolas}

Os tratores inicialmente possuíam rodas metálicas, utilizadas nas lavouras, não podiam circular em vias públicas ou terrenos úmidos pois as rodas rígidas não proporcionavam tração e estas rodas também eram inadequadas para fins de cultivo, uma vez que causavam diversos danos às raízes das culturas (MÁRQUEZ, 2010).

Os engenheiros da Allis Chalmers em 1930 começaram os experimentos com pneumáticos. Em 1932, um par de Firestone 48 x 12, pneus de avião, foi montado em um trator AC modelo U, obtendo um grande sucesso (ALLIS-CHALMERS, 2015).

Em 1933, a Allis Chalmers apresentou um trator montado com pneumáticos no Wisconsin State Fair trabalhando em um arado. Em seguida, um piloto local levou-o para $57 \mathrm{~km} / \mathrm{h}$, revelando a melhora no desempenho da máquina com a utilização de pneus. Essa publicidade gerada foi extremamente importante para a difusão e consequente aumento das vendas dos pneumáticos (ALLIS-CHALMERS, 2015).

Em 1935, quase 20.000 tratores (14\% da produção de tratores de rodas dos EUA) foram equipados com pneus de borracha na fábrica; em 1936, 31\%, em 1937, 42\%, em 1938, 65\% e em 1939, 83\%. Em 1940, mais de 90\% de todos os tratores de rodas foram vendidos com pneumáticos (ANTIQUEFARMING, 2015).

Ensaios da Universidade de Ohio revelaram que os tratores equipados com pneus de borracha podiam arar uma área 27\% maior, com redução no consumo de combustível de $23 \%$ em comparação aos tratores de rodas de aço. A Universidade de Illinois realizou ensaios comparativos entre tratores com rodas metálicas e tratores com pneus, 
verificando que tratores com pneus tiveram um aumento de $20 \%$ a $25 \%$ de potência disponível na barra de tração (ANTIQUEFARMING, 2015).

\subsection{Produção e mercado de pneus}

Mundialmente há uma tabela de classificação das empresas fabricantes de pneumáticos e esta classificação leva em conta as vendas, a comercialização e o faturamento anual das empresas. Abaixo, na Tabela 1, estão os 10 maiores fabricantes de pneus do mundo, de acordo com a European Tyre and Rubber Manufacturers Associantion (ETRMA 2014).

Tabela 1. Os dez maiores fabricantes de pneus e vendas de pneus nos anos 2012 e 2013 no mundo. Fonte: ETRMA (2014).

\begin{tabular}{ccccccc}
\hline & & & & Vendas & Vendas \\
2012 & 2013 & Empresa & País & $\begin{array}{c}2012 \\
\text { BE* }\end{array}$ & $\begin{array}{c}2013 \\
\text { BE* }\end{array}$ & Variação \\
\hline 1 & 1 & Bridgestone & Japão & 24.953 & 21.573 & $-14 \%$ \\
2 & 2 & Michelin & França & 21.044 & 19.842 & $-6 \%$ \\
3 & 3 & Goodyear & USA & 16.333 & 14.216 & $-13 \%$ \\
4 & 4 & Continental & Alemanha & 9.665 & 9.583 & $-1 \%$ \\
5 & 5 & Pirelli & Itália & 6.031 & 6.116 & $1 \%$ \\
6 & 6 & Hankook & Coreia do Sul & 4.841 & 4.847 & $2 \%$ \\
7 & 7 & Sumitomo & Japão & 5.768 & 4.840 & $-16 \%$ \\
8 & 8 & Yokohama & Japão & 4.338 & 3.423 & $-21 \%$ \\
9 & 9 & Maxxis International & Taiwan & 3.418 & 3.237 & $-5 \%$ \\
10 & 10 & Zhongce Rubber Group & China & 3.588 & 3.566 & $-1 \%$ \\
\hline
\end{tabular}

* BE: Bilhões de Euros

De acordo com a Associação Nacional da Indústria de Pneumáticos (ANIP), formada pela associação de 10 empresas fabricantes de pneumáticos, em 2015 houve a produção 68,7 milhões de unidades de pneumáticos no Brasil e o volume total produzido de 12,3 milhões foi destinado para a exportação. O volume de vendas de pneumáticos somando-se a produção no país com a importação de seus associados em 2014, foi de 74,9 milhões de unidades. A Tabela 2 mostra a produção de pneumáticos por categoria no Brasil do ano de 2007 a 2014. 
Tabela 2. Produção de unidades de pneus por categoria no Brasil, segundo ANIP (2015).

\begin{tabular}{l|llllllll}
\hline \multicolumn{1}{c}{ PRODUÇÃO POR CATEGORIA (Milhões de unidades) } \\
\hline & 2007 & 2008 & 2009 & 2010 & 2011 & 2012 & 2013 & 2014 \\
\hline CARGA & 7.319 & 7.367 & 6.033 & 7.735 & 7.448 & 7.138 & 8.231 & 7.894 \\
CAMIONETE & 6.058 & 5.841 & 5.599 & 7.940 & 8.470 & 8.267 & 9.904 & 8.860 \\
PASSEIO & 28.791 & 29.585 & 27.489 & 33.812 & 32.568 & 30.406 & 32.554 & 33.266 \\
MOTO & 13.725 & 15.249 & 13.158 & 15.205 & 16.078 & 14.519 & 15.041 & 15.642 \\
AGRÍCOLA & 698 & 776 & 593 & 781 & 793 & 807 & 928 & 873 \\
*C. CIVIL & 131 & 127 & 86 & 136 & 109 & 107 & 103 & 118 \\
INDUSTRIAL & 462 & 716 & 1.083 & 1.633 & 1.396 & 1.360 & 2.072 & 2.069 \\
AVIÃO & 60 & 47 & 41 & 60 & 60 & 54 & 52 & 50 \\
\hline TOTAL & 57.247 & 59711 & 54.085 & 67.305 & 66.926 & 62.661 & 68.888 & 68.776 \\
\hline * Construção Civil & & & & & & & &
\end{tabular}

Os pneus agrícolas e florestais fabricados em 2014 representaram 1,27\% do total produzido pela indústria nacional de pneus. A fabricação e comercialização de pneus agrícolas e florestais representam $2 \%$ da produção e comércio de pneumáticos no mundo. Pneus agrícolas e florestais têm uma menor demanda de mercado, pelo fato de possuírem maior vida útil de trabalho e a quantidade de máquinas agrícolas e florestais apresentarem número menor de unidades, quando comparadas a veículos de passeio e caminhões (Continental Tires Fact Book, ANIP 2015). A Figura 1 apresenta a participação de cada segmento específico de pneu no volume total das vendas globais.

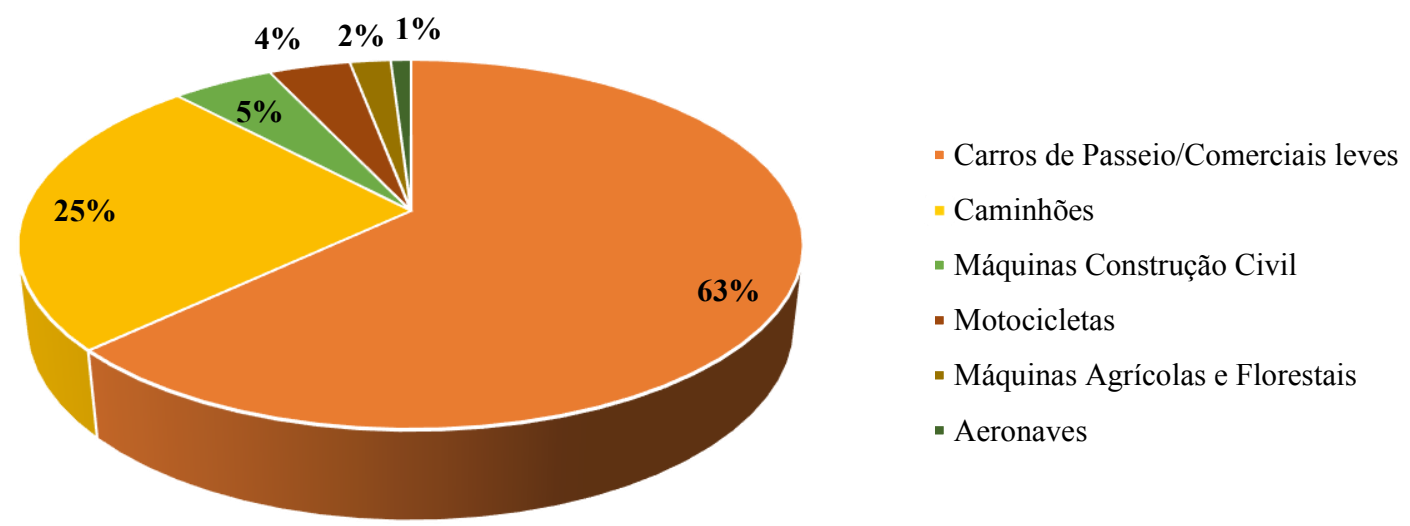

Figura 1. Porcentagem da participação de cada segmento na venda global de pneus.

Fonte: Continental (2015). 


\subsection{Importância do pneu nas máquinas agrícolas e florestais}

O sistema de rodado de um trator é o elemento responsável pela sustentação, propulsão, direcionamento e desenvolvimento de força na barra de tração, o que confere a este componente uma significativa relevância (LOPES et al., 2003).

De acordo com Corrêa (1999), o rodado é a união do aro com o pneu, sendo a última parte de ligação do motor do trator com o solo, e, seu estudo é de fundamental importância para o desempenho do trator. Portanto, há necessidade de conhecê-lo devido à interferência que pode causar no desempenho da máquina.

Segundo Sakai et al. (2008), os pneus florestais compõem grande parte da frota de máquinas florestais e são responsáveis por transmitir o torque da máquina ao solo. Sua estrutura é resistente contra perfurações e tem a capacidade de proporcionar maior agilidade de deslocamento dentro do talhão de colheita florestal e, por sua vez, confere maior conforto ao operador, quando comparada com máquinas de esteiras metálicas.

Os pneus agrícolas constituem um dos principais componentes do trator e da maioria das máquinas e implementos agrícolas e influenciam nos custos operacionais de campo, principalmente, nos custos finais de fabricação das máquinas, podendo chegar até a um terço de seus valores finais (JESUÍNO, 2007). Pneus agrícolas são o elo entre o trator e o solo, além de serem também responsáveis pelo tracionamento que o trator irá proporcionar para o arraste das demais máquinas e implementos agrícolas, realizando, assim, as operações no campo para as quais foram construídos (GABRIEL FILHO et al., 2010).

\subsection{Características dos pneus}

De acordo com Márquez (2011), o pneu é formando por uma mistura de borracha sobre uma estrutura de fios em camadas. Os fios se estendem de um lado a outro do pneu enrolando-se a um resistente arame de aço recoberto com cobre, o que facilita a aderência da borracha ao arame que forma o talão. Este conjunto de camadas forma o que se conhece como "carcaça", que suporta a carga e assegura resistência e flexibilidade. 
Silveira (2001) define pneu como um aro de borracha com o qual se reveste as rodas dos veículos e, com uma câmara de ar, forma um conjunto inflável, dotado de um bico externo e de uma válvula, formado por talões, carcaça, banda de rodagem e flanco ou lateral.

O pneu é constituído de 4 partes principais de acordo com Mitas (2013), sendo:

- Banda de rodagem: é a parte do pneu que entra diretamente em contato com o solo. Formada por um composto especial de borracha que oferece grande resistência ao desgaste.

- Flancos: protegem a carcaça de lonas. São dotados de uma mistura especial de borracha com alto grau de flexibilidade.

- Carcaça: é a parte de resistência do pneu, constituída de lonas de poliéster, nylon ou aço. Retém o ar sob pressão que suporta o peso total das máquinas agrícolas.

- Talão: são constituídos internamente de arames de aço de grande resistência e tem por finalidade manter o pneu acoplado no aro.

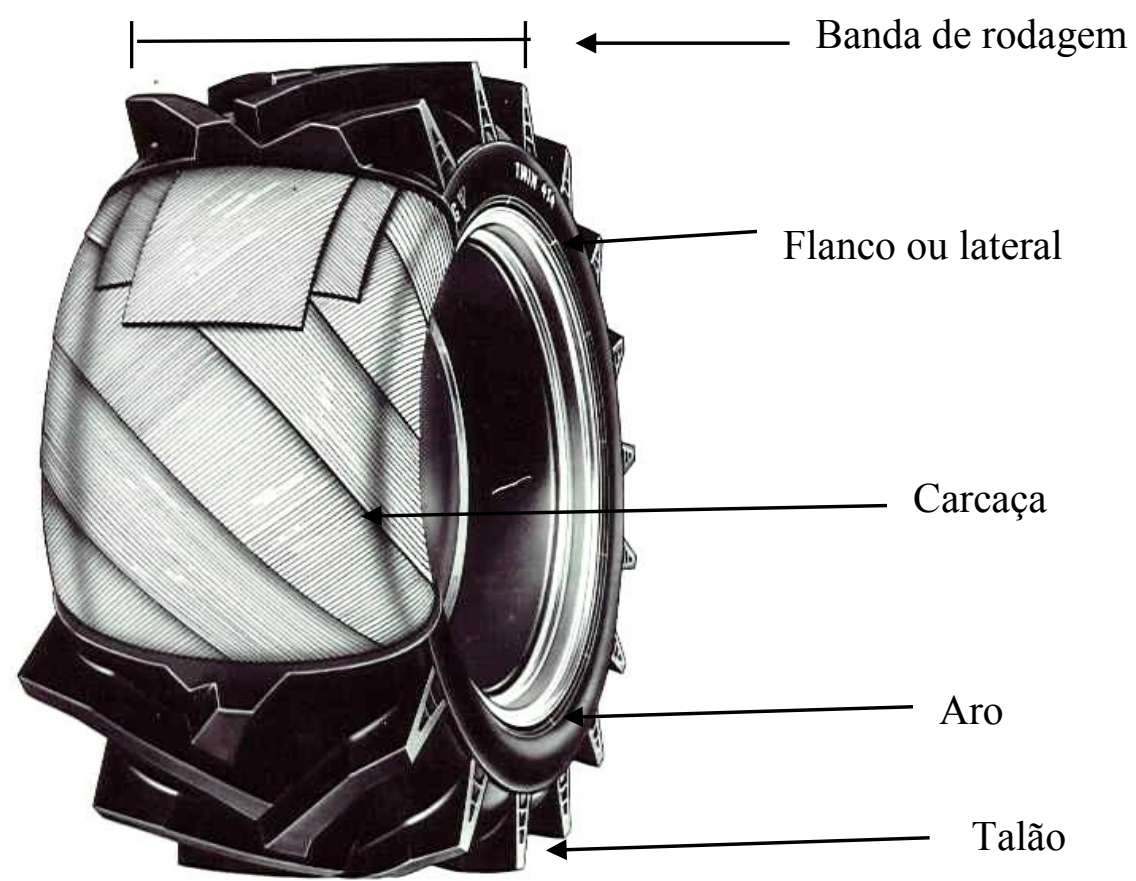

Figura 2. Partes constituintes dos pneus.

Fonte: Trelleborg do Brasil (2013). 
Os pneus agrícolas e florestais também são classificados de acordo com suas dimensões e disposição interna dos cordonéis e lonas, que formam a estrutura interna do pneu, segundo a Associação Latino Americana dos Fabricantes de Pneus, Aros e Rodas (ALAPA, 2013), geralmente descritas na lateral do pneu.

Em pneus agrícolas e florestais a banda de rodagem dispõe de ressaltos chamados de garras ou tacos, que permitem que o pneu se crave no solo relativamente preparado e, com isso, haja um aumento na capacidade de tração e um melhor ponto de apoio sobre o solo (MÁRQUEZ, 2011).

Tabela 3. Classificação de pneus para implementos e máquinas agrícolas e florestais, de acordo com o tipo de desenho da banda de rodagem. Fonte: ALAPA (2013).

\begin{tabular}{cc}
\hline & Pneus para Implementos Agrícolas \\
\hline Tipo & Especificações \\
I-1 & Multi-banda \\
I-2 & Tração Normal \\
I-3 & Tração de implementos pesados \\
I-4 & Rodas de arados \\
I-5 & Rodas direcionais \\
I-6 & Com garras superficiais \\
\hline Pneus Agrícolas para Remoção de Madeiras (Pneus Florestais) \\
Tipo \\
LS-1 \\
LS-2 \\
LS-3 \\
Tração Regularicações \\
Tração Intermediária \\
\hline
\end{tabular}

Segundo Horn et al. (2004), a banda de rodagem dos pneus é desenvolvida de acordo com o trabalho que ele irá realizar e o tipo de máquina que vai equipar. Esse fato implica na disposição, forma e arranjo das garras ou tacos sobre a banda de rodagem. 
As classificações dos pneus agrícolas e florestais de acordo com os desenhos das suas bandas de rodagem e suas finalidades estão representadas na Tabela 3.

\subsection{Tipos construtivos de pneus}

De acordo com ALAPA (2013), existem três tipos distintos de construção estrutural de pneus agrícolas, sendo eles: diagonal, baixa pressão e alta flutuação (BPAF) e radial. O pneu diagonal apresenta os cordonéis dispostos de talão a talão em ângulos menores que $90^{\circ}$ (aproximadamente $30^{\circ}$ a $40^{\circ}$ ) em relação à linha central da banda de rodagem.

No pneu baixa pressão e alta flutuação (BPAF) os cordonéis são dispostos igualmente ao pneu diagonal, abaixo da banda de rodagem e sobre os cordonéis existem cintas estabilizadoras, que proporcionam uma característica mais plana da banda de rodagem com a superfície. Esse tipo de pneu apresenta banda de rodagem radial e flanco diagonal, permitindo assim, maior flexibilidade e resistência ao mesmo.

O pneu radial apresenta os cordonéis dispostos de talão a talão em ângulo de $90^{\circ}$ em relação à linha central da banda de rodagem, o que lhe confere flexibilidade lateral; as cintas estabilizadoras sob a banda de rodagem proporcionam uma característica plana da área de contato do pneu com a superfície.

A Figura 3 ilustra os três tipos construtivos de pneus agrícolas:

\section{A. DIAGONAL}

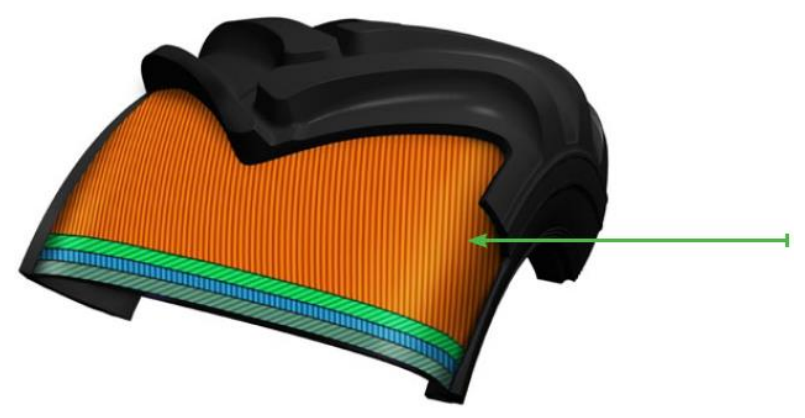

Os cordonéis estão dispostos de talão a talão em ângulos menores que $90^{\circ} \mathrm{em}$ relação à linha central da banda de rodagem. 
B. BPAF

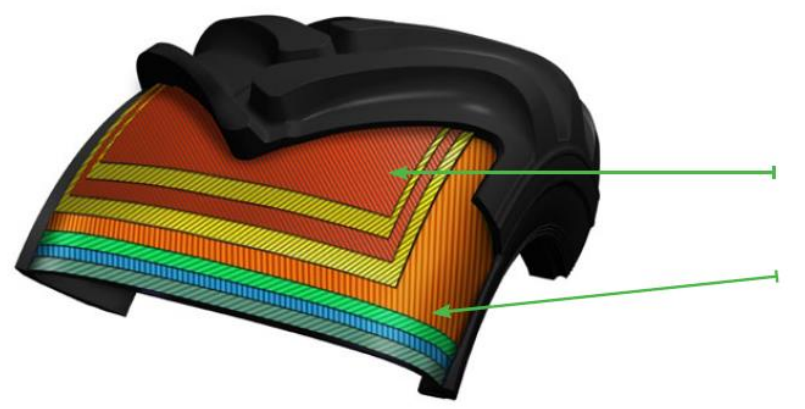

Cintas estabilizadoras

Estrutura diagonal

\section{RADIAL}

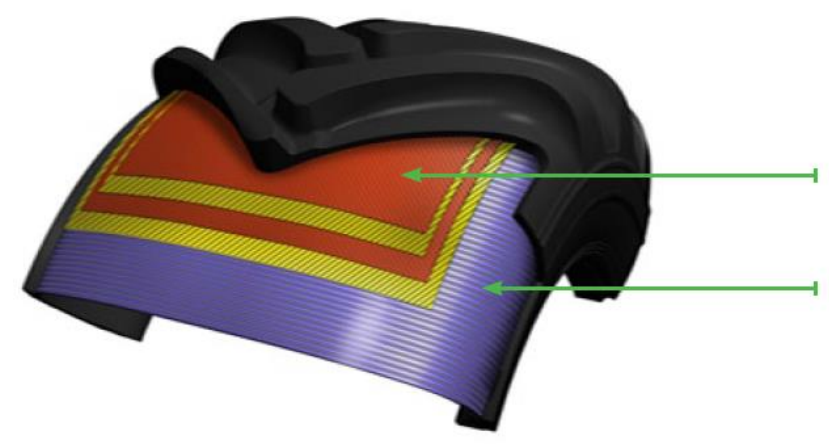

Cintas estabilizadoras

Os cordonéis estão dispostos de talão a talão em ângulos de $90^{\circ}$ em relação à linha central da banda de rodagem.

Figura 3. Pneu Diagonal (A), BPAF (B) e Radial (C).

Fonte: Nokian Tires (2013)

\subsection{Pneus agrícolas e florestais}

Os pneus agrícolas apresentam diferenças estruturais quando comparados aos pneus florestais. Os pneus florestais em sua totalidade possuem estrutura diagonal cintada, ou seja, estrutura diagonal têxtil na carcaça com uma ou mais cintas de aço sob a banda de rodagem para proteção e aumento da resistência contra perfurações e cortes. Há 
uma carcaça diagonal para pneu florestal, mas com características (devido ao seu perfil, lonagem e quantidade de cintas metálicas de proteção) similares à de um pneu radial, como a grande variação do raio estático com e sem carga. A alta flexibilidade dos flancos confere aos pneus florestais características hibridas de pneus de construção diagonal e reações parecidas com de pneus radiais, mesmo sendo diagonal cintado (BORGHI, 2012). Na Figura 4 observa-se as características construtivas desses pneus.

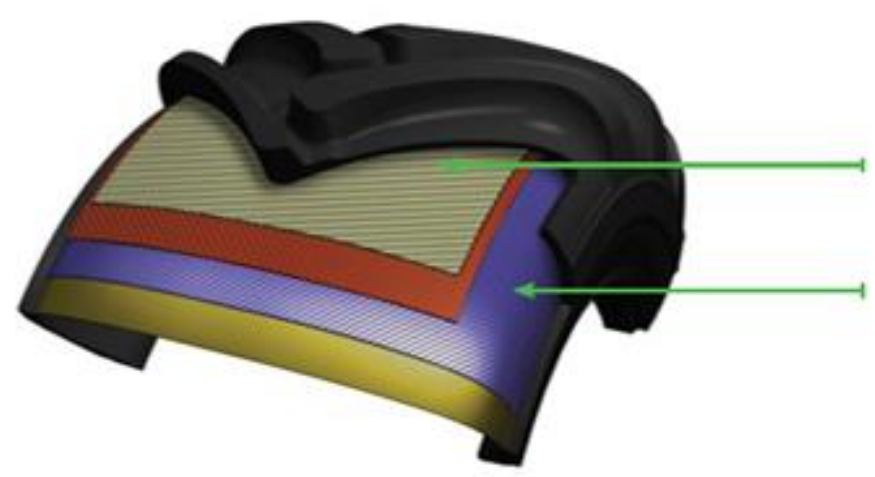

Cintas de aço

Cordonéis são dispostos em ângulos alternados com menos de $90^{\circ}$ em relação ao centro do pneu.

Figura 4. Princípios construtivos dos pneus florestais.

Fonte: Nokian Tires (2013).

Jun et al. (2004) avaliaram a área de contato de um pneu florestal com dimensões 600/55-26,5 utilizando um forwarder (trator florestal articulado utilizado no transporte de madeira cortada). As pressões de inflação utilizadas no trabalho foram de $100 \mathrm{kPa}$ (14,5 psi) e $240 \mathrm{kPa}$ (35 psi), as cargas aplicadas foram de $23.9 \mathrm{kN}$ e $40 \mathrm{kN}$ e a superfície utilizada foi um solo de textura argilosa. Para a determinação da área de contato do pneu, foram instalados seis transdutores que enviaram sinal quando a banda de rodagem tocava na superfície do solo, sendo que três transdutores foram colocados nas garras e os outros três foram colocados nas entre garras do pneu, sendo os sensores paralelos uns aos outros. Os autores concluíram que com a pressão de inflação de $100 \mathrm{kPa}$ e aplicação de uma carga constante de $23,9 \mathrm{kN}$, houve um 
aumento da área de contato, isto também ocorreu com o aumento na carga aplicada para $40 \mathrm{kN}$, mantendo uma pressão de inflação $100 \mathrm{kPa}$.

Os mesmos autores evidenciaram que houve um aumento na área de contato quando se elevou a carga dinâmica para $40 \mathrm{kN}$, o que proporcionou maior deslocamento das laterais do pneu. No trabalho foram avaliadas a tração líquida e a eficiência de tração do pneu, e os resultados mostraram que a tração dos pneus reduziu quando houve aumento na pressão de inflação de $100 \mathrm{kPa}$ para $240 \mathrm{kPa}$ e aplicação de carga de 23,9 kN. Quando se manteve a pressão de inflação em $100 \mathrm{kPa}$, o poder e a eficiência de tração aumentaram, com a elevação da carga dinâmica aplicada a pneu para 40 kN.

Algumas empresas do segmento florestal no Brasil começaram a buscar alternativas que diminuíssem as perdas de pneus florestais, geralmente perdidos ou sucateados por perfurações, cortes e arrancamentos de borracha. Utiliza-se a técnica da duplagem (acrescentar maior quantidade de lonas internamente ao pneu) para aumentar a resistência do pneu a perfurações. Outra alternativa foi substituir pneus florestais por pneus de aviões pelo fato destes apresentarem alto índice de capacidade de carga, o que reflete em grande quantidade de borracha, uma vez que, os pneus de avião são mais resistentes à perfurações, arrancamentos e cortes e operam com alta pressão de inflação (em torno de 759 kPa (110 psi) a 1034 kPa (150 psi)). O uso desta alta pressão de inflação é prejudicial às propriedades físicas do solo, ocasionando, muitas vezes, o processo de compactação do solo.

\subsection{Pressão de inflação}

De acordo com Lopes et al. (2005), a pressão de inflação dos pneumáticos é um fator determinante para o desempenho dos tratores agrícolas. Em estudo realizado por esses autores, a pressão de inflação influenciou significativamente no aumento da velocidade de deslocamento, potência disponível na barra de tração e redução na patinagem. A interação entre pressão de inflação e carga aplicada sobre os rodados mostrou que determinadas combinações desses dois fatores são favoráveis para o desenvolvimento de maior velocidade de deslocamento e menor patinagem.

Segundo Cambi et al. (2014), os pneus florestais utilizam alta pressão de inflação porque devem suportar grande quantidade de massa da máquina em que estão 
instalados, trabalham em terrenos irregulares com presença de tocos e pedras que facilmente podem causar danos, como arrancamentos de borracha e perfurações.

Yanai et al. (1999) verificaram a influência dos fatores pressão de inflação e carga sobre o rodado motriz, com a tração dianteira auxiliar de um trator ligada e desligada. Concluíram que a pressão de inflação dos pneumáticos influenciou significativamente nos seguintes parâmetros: índice de patinagem, velocidade de deslocamento e potência na barra de tração.

Grecenko e Prikner (2014) afirmam que a pressão de inflação dos pneus pode afetar o desempenho de tração, alterar a área de contato do pneu com a superfície, diminuir a área de contato do pneu com o solo. A variação da pressão de inflação é um fator crítico na determinação de tração dos pneus e pode gerar compactação nos horizontes do solo, bem como, influenciar no índice de patinagem dos rodados, pois a potência gerada pelo motor não é utilizada para realização de tração pela máquina. Esses efeitos limitam o poder de tração e desempenho dos pneus.

De acordo Stoilov e Kostadinov (2009), com a redução da pressão de inflação de pneus florestais em um Skidder, máquina utilizada na Bulgária para tracionar toras, ocorreu um aumento na área de contato dos pneus com o solo, maior deslocamento lateral dos pneus, elevação do poder de tração da máquina, redução do índice de patinagem e compactação do solo.

Serrano (2008) avaliou os efeitos da variação de pressão de inflação dos pneus no desempenho do conjunto trator-grade de discos. As pressões avaliadas foram: $100 \mathrm{kPa}$ nos pneus dianteiros e $140 \mathrm{kPa}$ nos pneus traseiros (recomendação do fabricante), $140 \mathrm{kPa}$ nos quatros pneus, $190 \mathrm{kPa}$ nos quatros pneus. O autor concluiu que a utilização de elevadas pressões de inflação nos pneus ocasiona uma redução de 3 a 5\% na capacidade de trabalho e um aumento significativo entre 10 e $25 \%$ do consumo de combustível por hectare, mesmo em condições de boa aderência dos pneus.

Com a utilização adequada da pressão de inflação e capacidade de carga (lastro), pode-se obter um rendimento maior e um prolongamento da vida útil do pneu, além disso, minimizam-se os problemas de perda de tração, aumento de patinagem e consumo de combustível, segundo Spagnolo et al. (2012). O referido autor avaliou o consumo de combustível de um trator agrícola operando com pneus novos e desgastados e observou que o 
consumo de combustível foi menor para os pneus novos, devido a presença de maior altura de garra nesses pneus.

Cuong (2013) realizou um trabalho para avaliar os níveis de vibração de um trator sem suspensão em função da variação de pressão de inflação dos pneus, utilizando nos pneus do eixo dianteiro uma pressão mínima de $90 \mathrm{kPa}$ e máxima de $210 \mathrm{kPa}$ e para os pneus do eixo traseiro uma pressão mínima de $60 \mathrm{kPa}$ e máxima de $180 \mathrm{kPa}$. Os resultados obtidos pelo autor evidenciaram que as baixas pressões de inflação dos pneus contribuíram para a redução dos níveis de vibração do trator.

Os pneus de baixa pressão apresentam carcaça mais flexível e operam, obviamente, a pressões mais baixas. A maior área de contato e a menor pressão sobre o solo objetivam minimizar a compactação do solo. Possuem alta capacidade de absorção de choques, pois a carcaça flexível e a baixa pressão resultam num efeito amortecedor, que reduz o desgaste do trator e a fadiga do operador (CORRÊA, 2000).

Segundo Baley et al. (1996), o uso correto da pressão de inflação e o índice de carga recomendado pelo fabricante não afetam significativamente o grau de compactação do solo. Pytka et. al. (2006) justificam que o uso da baixa pressão de inflação do pneu aumenta o poder de tração de $20 \%$ a $30 \%$ e minimiza em $9 \%$ a compactação do solo.

\section{9 Área de contato}

A área de contato do pneu com o solo é a responsável, em grande parte, pelo desempenho do trator, interferindo também no índice de patinagem de pneus e no poder de tração da máquina (SANTOS, 2003).

Upadhyaya e Wulfsohn (1990) realizaram experimento com três pneumáticos de construção radial, com dimensões distintas. A área de contato do pneu foi determinada utilizando-se um prato de aço coberto por papel carbono e folhas brancas, acima dos quais, o pneu era prensado para promover a impressão das áreas nas folhas.

A área de contato de um pneumático é um parâmetro chave para a determinação do tamanho da impressão (footprint) e da carga que o pneu está aplicando no solo. Através da verificação da intensidade desta impressão pode-se calcular uma estimativa da compactação do solo. À medida que aumenta a área de contato do pneu com o solo, através do 
uso de pneus com maior largura da banda de rodagem, ou até mesmo com a utilização de menor pressão de inflação e lateral mais flexível, há uma distribuição de maneira uniforme da carga do rodado sobre o solo, consequentemente a resistência ao rolamento e o consumo de combustível reduzem (DISERENS, 2009).

Paula (2008) construiu um perfilômetro laser para determinação da área e volume de contato dos rodados agrícolas com o solo. As áreas impressas no solo pelos pneus foram determinadas por meio dos métodos da foto, da super elipse e pelo método do perfilômetro laser. $\mathrm{O}$ método da super elipse subestimou os valores de área de contato entre o pneu e o solo, enquanto os métodos da foto e do perfilômetro laser apresentaram valores estatisticamente iguais, indicando que o perfilômetro laser é um método tão preciso quanto o método da foto.

Mazzeto (2004) avaliou metodologias de determinação das áreas de contato e deformações elásticas de pneus agrícolas em superfícies rígida e deformável, em função das pressões de inflação e cargas radiais, com a finalidade de identificar a metodologia mais acurada e prática para cada condição de ensaio estático de pneus. Foram utilizados pneus do tipo R1 com as seguintes dimensões: pneu de baixa pressão e alta flutuação (500/60-26.5) inflado com as pressões de 206,7 kPa, 103,3 kPa e 68,9 kPa, pneu radial (14.9R26) com pressões de inflação de $186,1 \mathrm{kPa}, 137,8 \mathrm{kPa}$ e $68,9 \mathrm{kPa}$ e diagonal (14.9-26) com pressões de 206,7 kPa, $137,8 \mathrm{kPa}$ e $68,9 \mathrm{kPa}$. Os pneus foram submetidos às cargas de $5 \mathrm{kN}, 10 \mathrm{kN}, 15 \mathrm{kN}$ e $20 \mathrm{kN}$ aplicadas por uma prensa hidráulica. As áreas de contato dos pneus agrícolas em superfície deformável foram obtidas em tanque de solo e em superfície rígida. $\mathrm{O}$ autor concluiu que as áreas de contato dos pneus em superfície deformável apresentaram correlações estatísticas significativas com as áreas obtidas em superfície rígida.

\subsection{Deslocamentos laterais do pneu}

No momento em que se realiza a montagem do pneu no aro e se procede o enchimento, este alcança as dimensões estabelecidas por projeto inicial, sendo simplificadamente constituídas por um diâmetro total e uma largura de pneu. No entanto, quando o pneu é instalado no trator, a carga que gravita sobre ele causa uma deformação, produzindo-se um achatamento de 5 a $10 \mathrm{~cm}$ na lateral do pneu, sendo este fato denominado 
deformação ou deslocamento horizontal, de maneira que a superfície de contato aumenta assumindo uma forma elíptica em pneus diagonais ou forma quase retangular em pneus radiais (CUETO, 2013).

A elasticidade de rodados pneumáticos e sua deformação tem grande importância no estudo da capacidade de tração, estabilidade do trator, segurança e preservação da integridade física do operador (MAZZETO, 2004). Kim e Rehkugler (1987) concluíram que a maior influência na deformação e elasticidade dos rodados pneumáticos, principalmente em superfícies rígidas, está relacionada com as dimensões, tipo de construção, rigidez de carcaça, pressão de inflação e com a carga dinâmica imposta sobre o mesmo.

Barbosa (2012) ensaiou dois pneus, com garra (CG) e sem garra (SG) na banda de rodagem, com medidas de 400/60-15.5, aplicando uma carga de $29 \mathrm{kN}$. O ensaio dos pneus foi realizado em uma superfície rígida e um dos parâmetros avaliados foi a deformação total dos pneus. $\mathrm{O}$ autor concluiu que o pneu (CG) apresentou maior deformação em consequência de sua menor rigidez estrutural, sendo que o pneu (CG) teve uma deformação total de $58 \mathrm{~mm}$ e o pneu (SG) teve uma deformação total de $50 \mathrm{~mm}$.

Lyasko (1994) avaliou as deformações laterais e a área de contato de um pneu agrícola sobre uma superfície rígida. O autor concluiu que a deformação vertical e horizontal e área de contato variaram de acordo com o valor de carga aplicado, largura da banda de rodagem, diâmetro externo, construção da carcaça e pressão de inflação. A seguir, a Figura 5 representa os deslocamentos vertical e horizontal do pneu. 


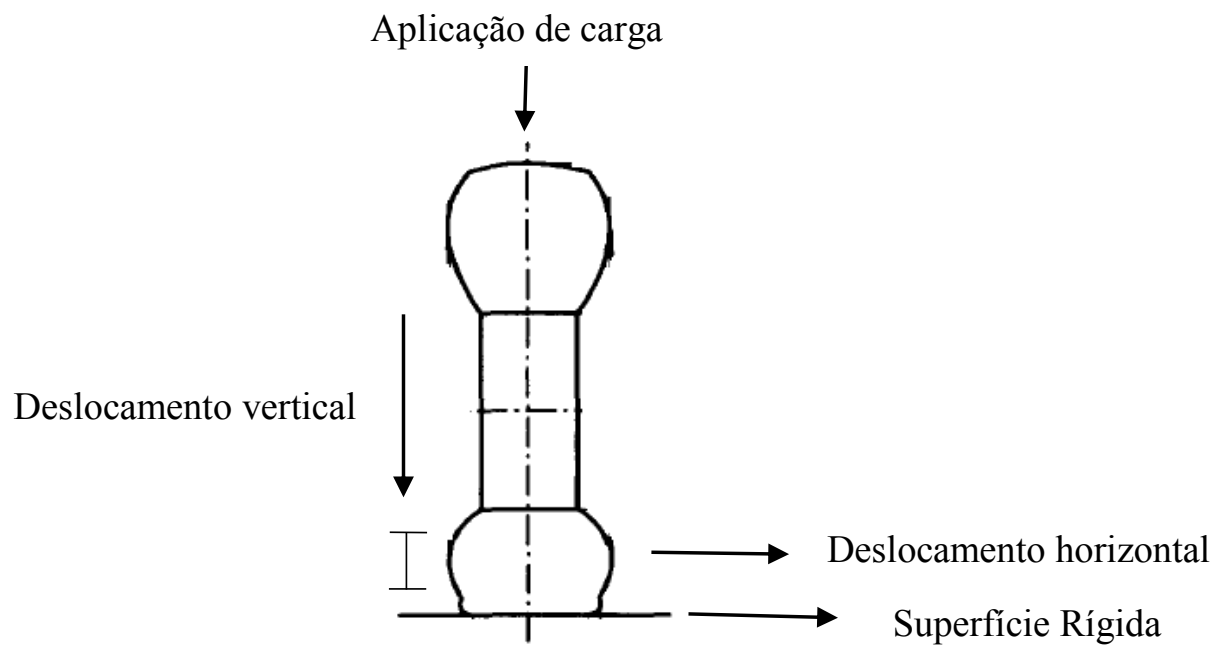

Figura 5. Deslocamento vertical e horizontal do pneu com aplicação de carga.

Fonte: Lyasko (1994).

\subsection{Compactação do solo}

Compactação do solo é definida como um aumento da densidade do solo, causado pelo homem ou por animais, resultado do rearranjamento das partículas do solo e consequente redução da porosidade; adensamento é o aumento da densidade do solo por processos pedogenéticos, como a dessecação, iluviação ou precipitação química (LIER et al. 2010).

Segundo Laguë et al. (2003), a compactação na camada superficial do solo até 0,25 $\mathrm{m}$ de profundidade está relacionada com a pressão exercida entre o rodado e a superfície de contato, enquanto a compactação subsuperficial está relacionada à carga por eixo das máquinas.

Porterfield e Carpenterz (1986) realizaram um trabalho utilizando a pressão média de contato de um pneu com determinado tipo de solo e verificaram que o nível de compactação superficial depende da pressão de contato, enquanto que a compactação profunda depende da área de contato, largura do pneu e da carga suportada pelo mesmo.

De acordo com Fernandes et al. (2013), a redução do risco de compactação é efetivamente obtida quando se reduz a pressão aplicada por unidade de área e eleva-se a área de contato através da utilização de esteiras ou de pneus mais largos, duplos ou com menor pressão de inflação. Para uma mesma pressão de contato (100 kPa, por exemplo), 
as tensões são transmitidas em maiores profundidades com o aumento da área de contato. A distribuição da tensão no solo é afetada pela área de contato dos pneus, pela dureza da carcaça do pneu e também pela velocidade de tráfego.

Estudos de compactação do solo realizados por Greacen e Sands (1980) em operações florestais mecanizadas na Austrália detectaram pressão entre $85 \mathrm{kPa}$ e $100 \mathrm{kPa}$ para um trator florestal arrastador de toras chamado skidder. As medições foram realizadas dividindo-se a massa total da máquina pela área de contato com o solo; as interferências dinâmicas causadas pelo movimento da máquina e as geradas pelo peso da madeira foram consideradas. Os autores afirmaram que a carga dinâmica, a pressão interna dos pneus e as múltiplas passadas afetam a densidade do solo, a qual varia significativamente de acordo com a classe de solo.

Segundo Fernandes (1996), a compactação de solos florestais na Austrália provém do contato pneu-solo nas operações de exploração e transporte. Adicionalmente, a compactação de solos florestais provoca um efeito a longo prazo e depende da interação de vários fatores tais como o clima, as propriedades químicas e físicas do solo, práticas de manejo e metodologia de exploração e transporte florestal.

A compactação em solos florestais difere dos solos agrícolas devido às diferenças e naturezas da cultura, em particular, ao peso e tamanho das plantas e ao ciclo cultural. As forças causadoras da compactação dos solos florestais ou agrícolas provêm do uso de máquinas, uma vez que, a mecanização foi intensificada nas últimas décadas (CASTRO NETO, 2001). 


\section{MATERIAL E MÉTODOS}

\subsection{Material}

\subsection{1 Área experimental}

O experimento foi conduzido no Núcleo de Ensaio de Máquinas e Pneus Agroflorestais (NEMPA), da Faculdade de Ciências Agronômicas FCA-UNESP, Fazenda Experimental Lageado, Câmpus de Botucatu - SP.

As coordenadas geográficas, onde a prensa hidráulica utilizada para ensaio de pneus está fixada, são altitude $813 \mathrm{~m}$, latitude $22^{\circ} 51^{\prime} 88^{\prime \prime} \mathrm{S}$ e longitude $48^{\circ} 26^{\prime} 22^{\prime \prime} \mathrm{O}$.

\subsubsection{Pneus Ensaiados}

Foram ensaiados dois modelos de pneus, sendo um para uso agrícola BPAF (baixa pressão e alta flutuação) e outro pneu BPAF recomendado para serviços florestais, ambos importados e fabricados pela mesma empresa. Esses modelos de pneus podem ser 
utilizados em reboques e máquinas agrícolas e florestais, em eixo de tração ou eixo livre, e possuem a mesma largura da banda de rodagem, diâmetro do aro e índice de velocidade. O pneu florestal possui cintas de aço e uma maior quantidade de composto de borracha, o que the confere resistência a furos e arrancamentos, fato que o difere do pneu agrícola, já que o mesmo não possui cintas de aço. As características de cada pneu estão apresentadas na Tabela 4. O pneu agrícola modelo Twin T 421 e o pneu florestal modelo Twin T 428 SB podem ser visualizados na Figura 6.

Tabela 4. Características técnicas do pneu agrícola e florestal utilizado no ensaio em superfície rígida. Fonte: Trelleborg do Brasil (2013).

\begin{tabular}{lcc}
\hline & \multicolumn{2}{c}{ Pneus } \\
\hline Características & BPAFAgrícola & BPAF Florestal \\
\hline Dimensão & $600 / 55-26.5$ & $600 / 55-26.5$ \\
Fabricante & Trelleborg & Trelleborg \\
Modelo & Twin T421 & Twin Forestry T428 SB* \\
Índice de velocidade & 166 & 165 \\
Índice de carga & A8 & A8 \\
Largura da banda (mm) & 638 & 630 \\
Diâmetro externo (mm) & 1379 & 1374 \\
Circunferência de rolamento (mm) & 3970 & 4020 \\
Massa do pneu (kg) & 132 & 180 \\
Raio estático com carga (mm) & 595 & 625 \\
Uso de câmara de ar & Não & Sim \\
Aro permitido & AG 20.00x26.5 & AG 20.00x26.5 \\
* SB: Cintas de aço & &
\end{tabular}




\section{A. TWIN T 421 AGRÍCOLA}

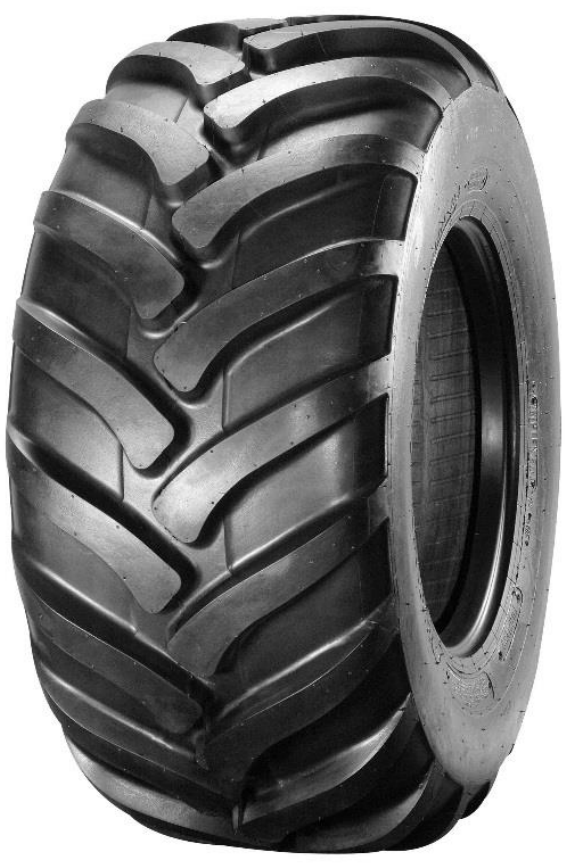

B. TWIN T 428 FLORESTAL

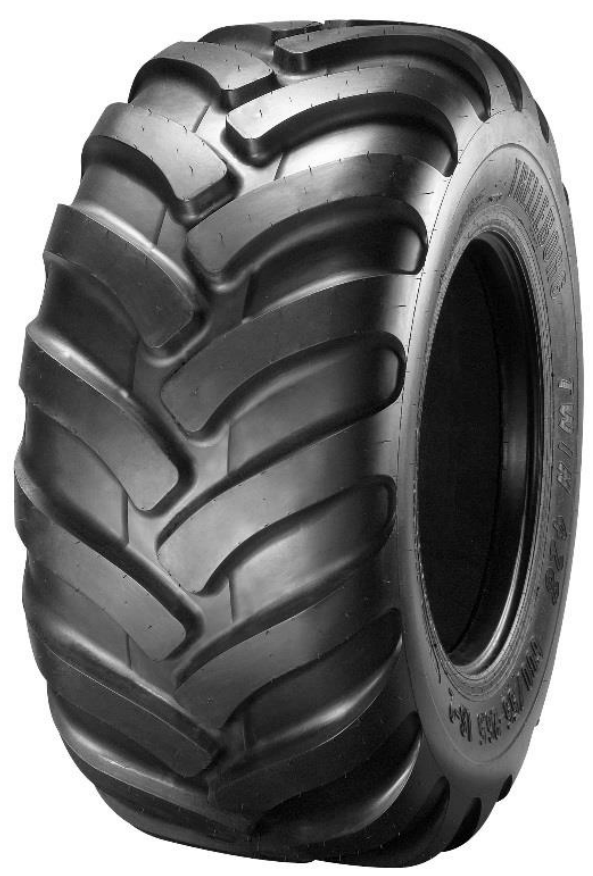

Figura 6. A: Pneu agrícola; B: Pneu florestal.

Fonte: Trelleborg, 2015

\subsubsection{Prensa hidráulica e superfície rígida}

A prensa hidráulica foi utilizada para realizar a prensagem dos pneus em uma superfície rígida e obtenção do deslocamento horizontal, vertical e área de contato dos pneus, simulando assim, as interações entre as máquinas e seus rodados. Sua constituição é de perfis e tubos de aço carbono e seu acionamento ocorre por meio de um sistema hidráulico, regulado por um software de computador ou manualmente pelo uso de botões. O funcionamento é promovido por um conjunto motor-bomba, alimentado por corrente elétrica. Em seu interior, existe um eixo, onde são acoplados os pneus para os ensaios, com o intuito de impor cargas concentradas. Entre o pistão hidráulico e a estrutura que serve de suporte para o eixo onde são acoplados os pneus, foi instalado uma célula de carga que coleta as informações de cargas aplicadas nos pneus. No interior da prensa, há uma estrutura metálica que suporta uma superfície 
plana constituída de aço carbono e, é sobre esta superfície, que se coloca o papel onde o pneu imprimirá sua área de contato. Na Figura 7 é possível visualizar a estrutura da prensa hidráulica utilizada para o ensaio dos pneus.

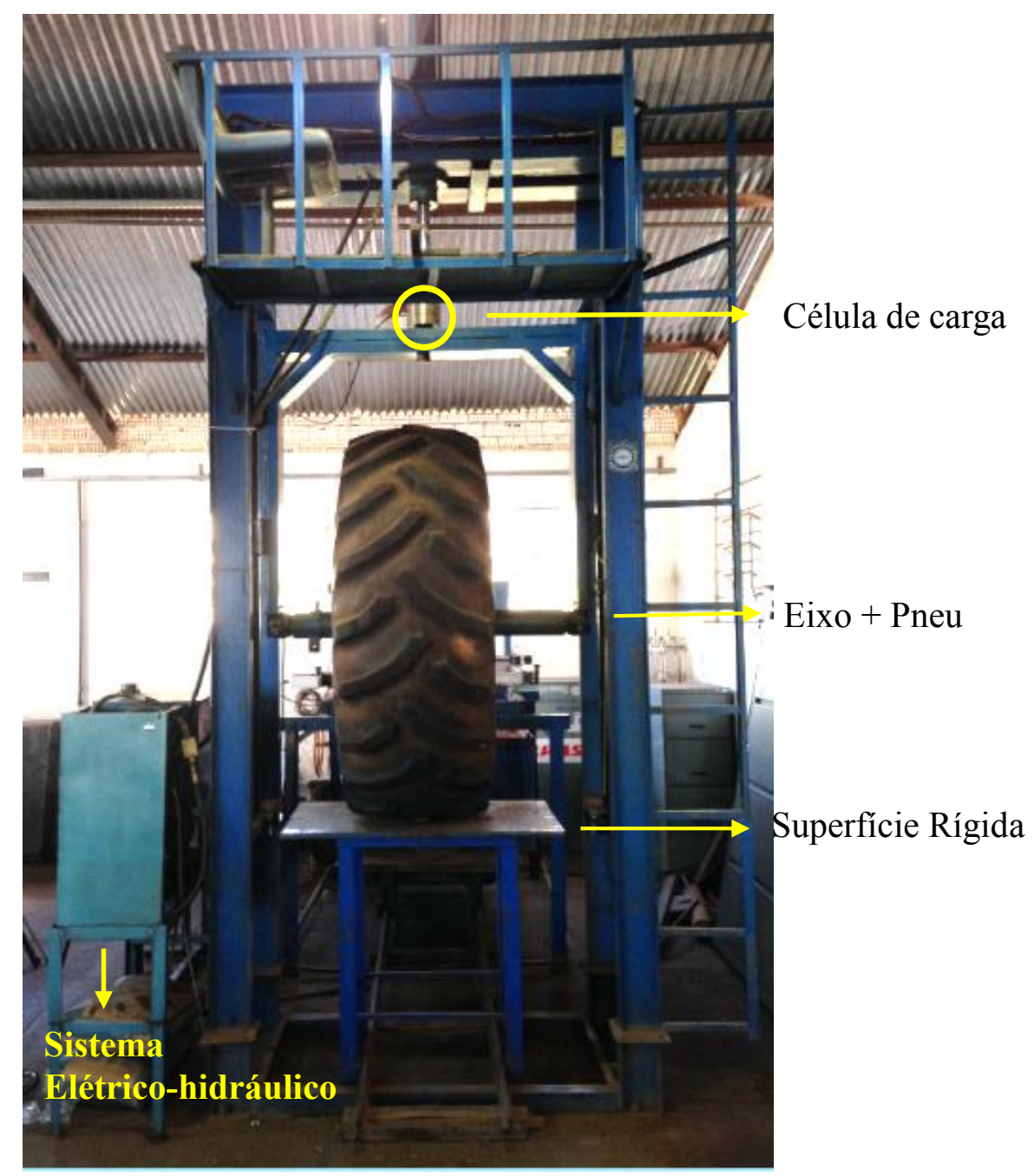

Figura 7. Prensa hidráulica e superfície rígida utilizada no ensaio de pneus.

\subsubsection{Sensores de deslocamento}

Foram instalados na prensa hidráulica de ensaio de pneus, dois potenciômetros (Figura 8) com escala de deslocamento, da marca Kyowa, modelo DT 100 A, com capacidade máxima de $100 \mathrm{~mm}$ de leitura. Um potenciômetro foi instalado horizontalmente 
e o outro verticalmente em relação a posição do pneu, com o intuito de coletar o deslocamento vertical e horizontal do pneu.

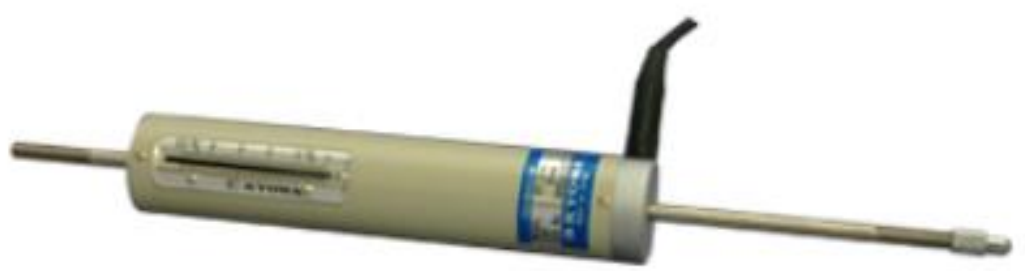

Figura 8. Potenciômetro da marca Kyowa, modelo DT 100 A.

O potenciômetro foi instalado horizontalmente na prensa hidráulica para coletar o deslocamento horizontal sofrido na lateral do pneu, como pode ser visualizado na Figura 9.

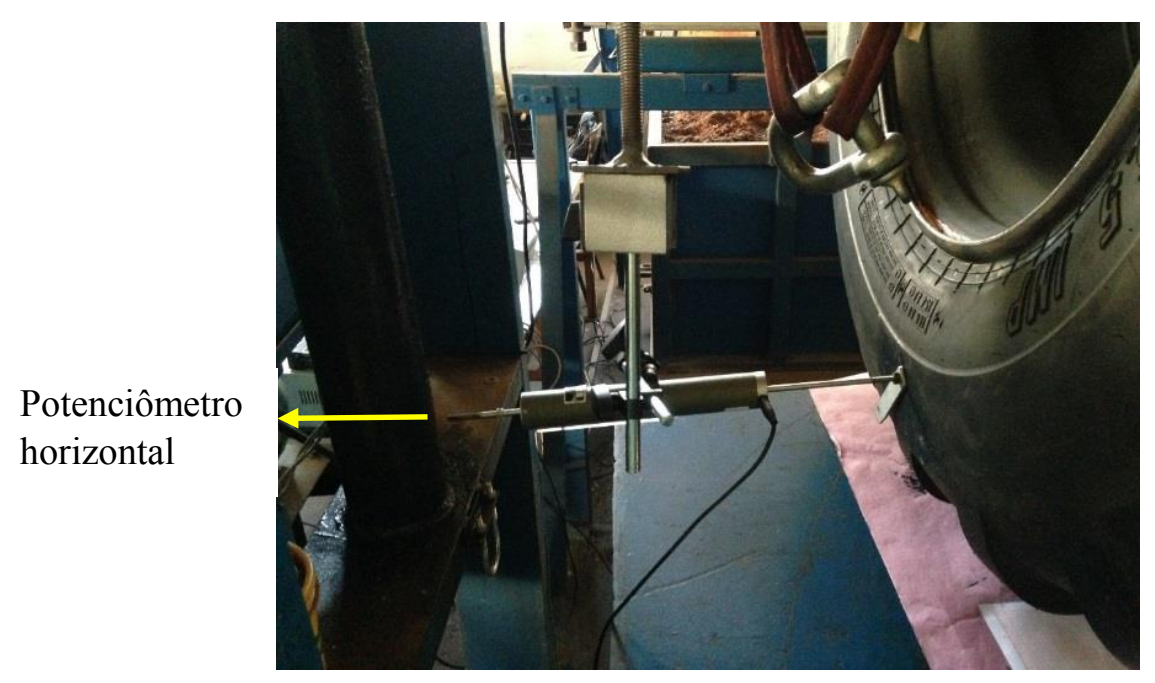

Figura 9. Potenciômetro utilizado para coletar o deslocamento horizontal do pneu.

Na vertical foi acoplado um potenciômetro à prensa hidráulica, a fim de coletar o deslocamento sofrido pelo pneu, neste sentido. A marca e o modelo do potenciômetro utilizado são iguais ao utilizado para coletar o deslocamento horizontal. Na Figura 10 pode se visualizar o potenciômetro acoplado a prensa. 


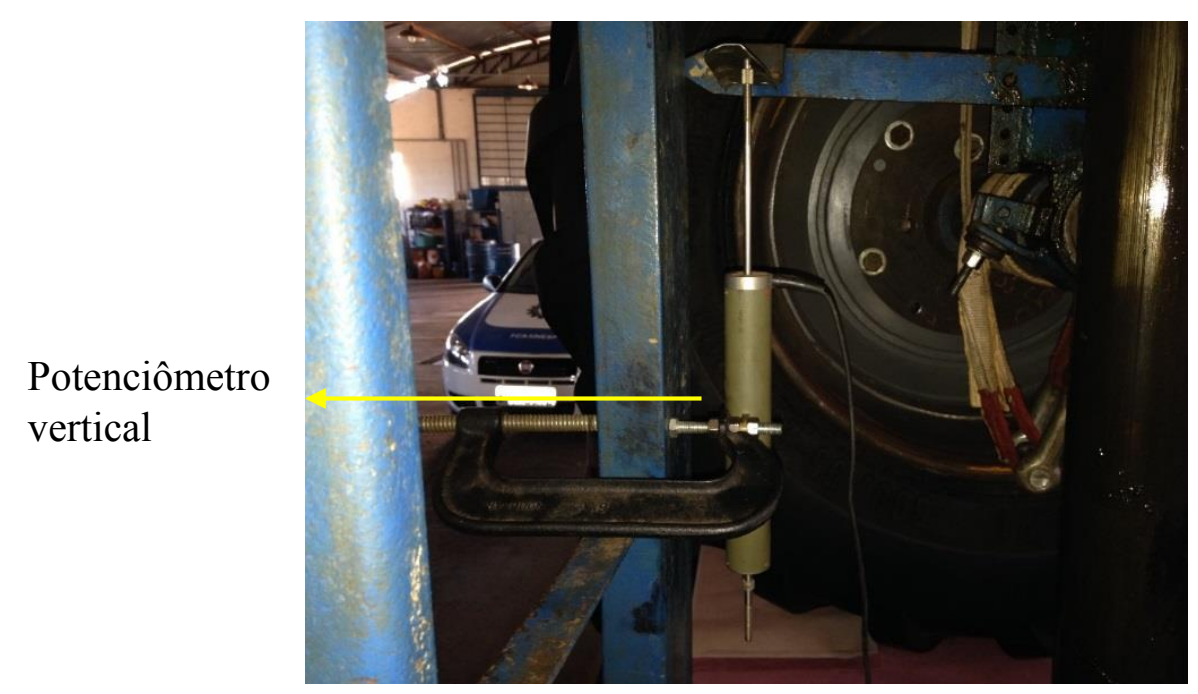

Figura 10. Potenciômetro utilizado para coletar o deslocamento vertical do pneu.

\subsubsection{Papel}

Uma folha de papel com $900 \mathrm{~mm}$ de comprimento e $900 \mathrm{~mm}$ de largura foi colocada sobre a superfície rígida para obtenção da impressão do pneu agrícola e florestal. Nesta mesma folha de papel foi colocado um papel milimétrico utilizado como escala, como mostra a Figura 11.

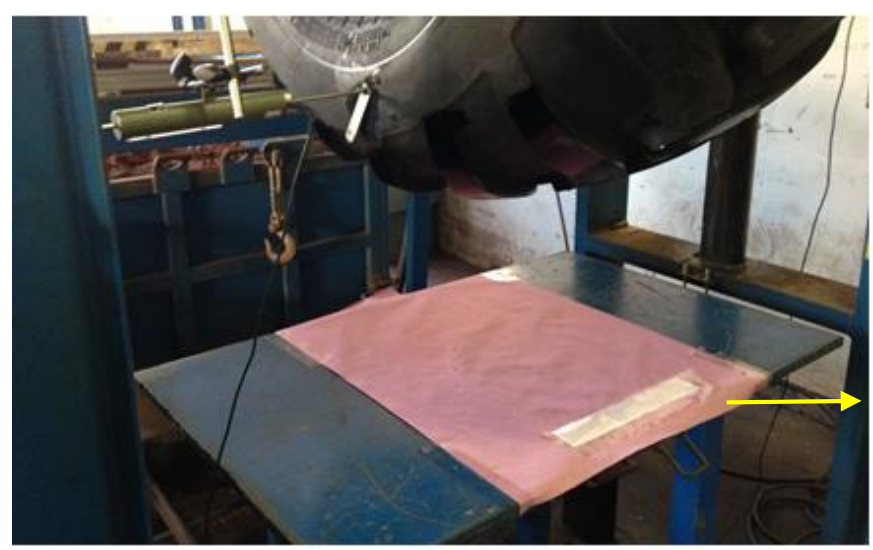

Escala

milimétrica

Figura 11. Papel sobre a superfície rígida com escala. 


\subsubsection{Manômetro de aferição de pressão dos pneus}

A pressão de inflação dos pneumáticos foi aferida por um manômetro de alta precisão, com escala de 1 psi e pressão máxima de até 414 kPa (60 psi).

\subsubsection{Tinta de carimbo}

A banda de rodagem do pneu agrícola e florestal foi pintada com tinta (tinta de carimbo) a fim de que as áreas de contato dos pneus ficassem impressas nas folhas de papel.

\subsubsection{Câmera fotográfica digital}

Para registrar e armazenar as imagens das impressões dos pneus deixadas na folha de papel foi utilizada uma câmera fotográfica digital da marca Nikon, modelo D 3200 de 24.2 megapixels.

\subsubsection{Programas computacionais}

Para coleta, armazenagem e processamento dos dados obtidos foram utilizados os programas ImageJ, realizando o cálculo da área de contato do pneu com a superfície e, LabView, programa computacional da prensa hidráulica que controla a aplicação de carga, coleta e armazenagem de dados adquiridos. A Figura 12 ilustra a tela do programa LabView. 


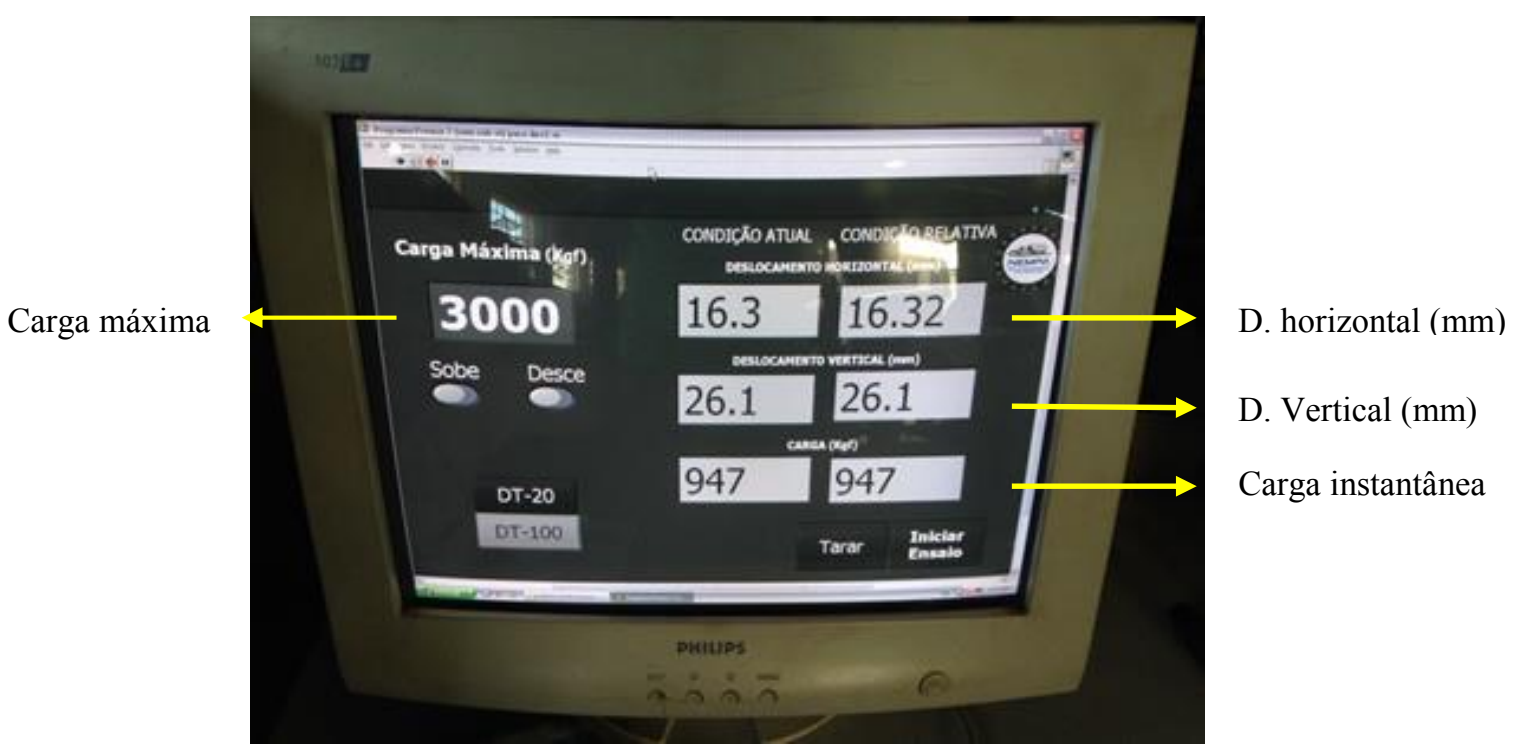

Figura 12. Dados do ensaio dos pneus apresentados no monitor da prensa.

\subsection{Métodos}

\subsubsection{Aplicação de carga nos pneumáticos}

Foi utilizada a prensa hidráulica para aplicação de cargas nos pneus agrícola e florestal. Para a leitura das cargas aplicadas aos pneumáticos foi instalada uma célula de carga, entre o pistão hidráulico e a estrutura que suporta o eixo onde é acoplado o pneu e, por meio de sinais elétricos contínuos enviados pela célula foi possível quantificar e armazenar as cargas aplicadas através das informações obtidas pelo programa de computador. Os deslocamentos horizontal e vertical foram obtidos por sensores instalados na prensa e, através de sinais elétricos enviados ao programa, obteve-se os deslocamentos dos pneus. O programa LabView, instalado no computador da prensa, controla a quantidade e intensidade da carga aplicada e em seguida armazena os dados, o que é repetido sucessivamente até se alcançar a carga máxima programada no ensaio. 


\subsubsection{Impressão da banda de rodagem em uma superfície rígida}

As áreas de contato dos pneus agrícola e florestal sobre a superfície rígida foram obtidas através da prensagem dos pneus em uma folha de papel. Antes de ocorrer a prensagem, a banda de rodagem do pneu foi pintada com tinta de carimbo a fim de estampar a impressão. Esta metodologia para determinação da área de contato foi descrita por Upadhayaya e Wulfsohn (1990) e também utilizada por Lyasko (1994).

\subsubsection{Obtenção das áreas de contato a partir da impressão}

Após cada prensagem dos pneus no papel, as áreas de contato obtidas foram registradas por uma câmera fotográfica digital e as imagens enviadas para o computador. A partir da digitalização, as fotos foram inseridas no programa e analisadas, incluindo todas as repetições de cada parcela do experimento. O programa utilizado para o cálculo das áreas de contato impressas na folha foi o ImageJ.

As áreas de contato do pneu agrícola e florestal foram determinadas pelos cálculos realizados pela digitalização das imagens, semelhante ao utilizado por Mazetto e Lanças (2000).

\subsubsection{Obtenção do deslocamento vertical e horizontal}

Foram acoplados à prensa hidráulica dois potenciômetros, um na posição horizontal e outro na posição vertical, sendo que através destes foram coletados os deslocamentos sofridos na região do pneu onde estes potenciômetros estavam instalados.

Antes de iniciar a prensagem dos pneus os potenciômetros foram ajustados e aferidos quanto à posição correta e aos valores apresentados no programa computacional, verificando se estavam com o valor inicial (zero) e a partir deste momento o ensaio foi iniciado.

Os potenciômetros em questão foram posicionados em regiões dos pneus e da prensa onde pudessem mensurar os deslocamentos sofridos de acordo com aplicação de cargas. 


\subsubsection{Pressões de inflação e cargas aplicadas no pneu agrícola e florestal}

Para os pneus agrícola e florestal foram utilizadas quatro pressões de inflação e, estas pressões foram recomendadas de acordo com a quantidade de carga aplicada sobre o pneu, o que significa que para cada pressão de inflação foi aplicada uma carga que o pneu suporta de acordo com sua pressão de enchimento interna. As cargas aplicadas pela prensa nos pneus foram impostas gradativamente, correspondendo às cargas mínima e máxima que o pneu sofre, de acordo com o trabalho desenvolvido pela máquina onde ele está montado. A recomendação do fabricante é que os pneus florestais utilizem pressões de inflação superiores às utilizadas nos pneus agrícolas devido ao fato destes pneus possuírem uma estrutura mais resistente quando comparados aos agrícolas. As pressões de inflação do pneu agrícola e florestal foram classificadas como mínima, intermediária, nominal e alta. Nas Tabelas 5 e 6 estão descritas as pressões de inflação e as cargas aplicadas nos pneus agrícola e florestal, respectivamente.

Tabela 5. Pressões de inflação recomendadas, segundo o fabricante, de acordo com a carga aplicada sobre o pneu agrícola. Fonte: Trelleborg (2015).

\begin{tabular}{llc}
\hline Classificação & Pressões de inflação kPa (psi) & Carga aplicada kN (kgf) \\
\hline Mínima & $48,2 \mathrm{kPa}(7 \mathrm{psi})$ & $25 \mathrm{kN}(2500 \mathrm{Kgf})$ \\
Intermediária & $193 \mathrm{kPa}(28 \mathrm{psi})$ & $50 \mathrm{kN}(5000 \mathrm{Kgf})$ \\
Nominal & $234,4 \mathrm{kPa}(34 \mathrm{psi})$ & $50 \mathrm{kN}(5000 \mathrm{Kgf})$ \\
Alta & $344,7 \mathrm{kPa}(50 \mathrm{psi})$ & $50 \mathrm{kN}(5000 \mathrm{Kgf})$ \\
\hline
\end{tabular}

Tabela 6. Pressões de inflação recomendadas, segundo o fabricante, de acordo com a carga aplicada sobre o pneu florestal. Fonte: Trelleborg (2015)

\begin{tabular}{llc}
\hline Classificação & Pressões de inflação kPa (psi) & Carga aplicada kN (kgf) \\
\hline Mínima & $158,5 \mathrm{kPa}(23 \mathrm{psi})$ & $35 \mathrm{kN}(3500 \mathrm{Kgf})$ \\
Intermediária & $241,3 \mathrm{kPa}(35 \mathrm{psi})$ & $50 \mathrm{kN}(5000 \mathrm{Kgf})$ \\
Nominal & $379,2 \mathrm{kPa}(55 \mathrm{psi})$ & $50 \mathrm{kN}(5000 \mathrm{Kgf})$ \\
Alta & $496,4 \mathrm{kPa}(72 \mathrm{psi})$ & $50 \mathrm{kN}(5000 \mathrm{Kgf})$ \\
\hline
\end{tabular}




\subsubsection{Análise estatística}

No experimento as variáveis deslocamento vertical, deslocamento horizontal e área de contato dos pneus em superfície rígida foram analisadas considerando-se o delineamento em blocos casualizados em esquema fatorial tendo como fatores 2 estruturas de pneus (agrícola e florestal), inflados com 4 pressões, de acordo com o manual do fabricante, e 6 repetições, conforme descritos nas Tabelas 5 (Pneu agrícola) e 6 (Pneu florestal).

Os resultados do experimento foram tabulados e interpretados estatisticamente por meio de análise de variância e ao teste de comparação de médias de Tukey a 5\% de probabilidade. O software utilizado para análise de variância foi o MINITAB 17. 


\section{RESULTADOS E DISCUSSÃO}

O procedimento de análise de variância com um fator depende da estimativa da dispersão e indica que há um fator ou característica que distingue cada um dos pneus, neste caso avaliado pela tabela de análise de variância ANOVA. De acordo com os resultados obtidos, observou-se que há variabilidade entre os pneus, ou seja, os pneus agrícola e florestal diferem entre si, onde, o valor quadrado médio encontrado, a um nível de significância de $5 \%$, para o deslocamento vertical entre os dois tipos de pneus foi de 873,1 , para o deslocamento horizontal 1072,76 e área de contato foi 0,264, sendo considerados significativos estatisticamente. Por sua vez, o valor do deslocamento vertical em função da pressão de inflação foi de 75,8,65,13 para deslocamento horizontal e 0,79 para a área de contato, e, quando avaliouse o tipo de pneu simultaneamente com a pressão de inflação os valores encontrados para deslocamento vertical, horizontal e área de contato foram, respectivamente, 1137,8 1581,53 e 0,756 , sendo estes valores também considerados significativos estatisticamente. Desta forma, os pneus agrícola e florestal sofreram influência das pressões utilizadas, sendo o pneu florestal menos sensível às variações de pressão, o que pode ser em detrimento de sua estrutura rígida. Esses resultados corroboram com o estudo de Jun et al. (2004), que realizou ensaio com pneu florestal nas mesmas dimensões e Fernandes (2013), que encontrou os mesmos resultados para pneu agrícola. Os valores acima referidos estão ilustrados na Tabela 7 
Tabela 7. Resumo da análise de variância para a variável deslocamento vertical, deslocamento horizontal e área de contato.

\begin{tabular}{ccccc}
\hline \multirow{2}{*}{$\begin{array}{c}\text { Causas de } \\
\text { variação }\end{array}$} & G. L. & \begin{tabular}{c} 
Q. M. \\
\cline { 3 - 4 }
\end{tabular} & & Deslocamento \\
vertical & $\begin{array}{c}\text { Deslocamento } \\
\text { horizontal }\end{array}$ & Área de contato \\
\hline Tipo de pneu & 1 & $873,1^{*}$ & $1072,76^{*}$ & $0,264^{*}$ \\
Pressão & 3 & $75,8^{*}$ & $65,13^{*}$ & $0,79^{*}$ \\
Tipo x Pressão & 4 & $1137,8^{*}$ & $1581,53^{*}$ & $0,756^{*}$ \\
\hline C. V (\%) & & 2,84 & 2,87 & 2,96 \\
\hline
\end{tabular}

Legenda. $\mathrm{L} .=$ Graus de liberdade; $\mathrm{Q} . \mathrm{M}=$ quadrados médios. $\mathrm{CV}=$ Coeficiente de Variação.

(*) Significativo ao nível de 5\% de probabilidade pelo teste $\mathrm{F}$.

\subsection{Deslocamento vertical do pneu agrícola e florestal}

Na Tabela 8 estão representados os valores médios de deslocamento vertical dos pneus agrícola e florestal. Os dois pneus foram ensaiados com quatro pressões de inflação recomendadas e especificadas no manual do fabricante, de acordo com suas estruturas construtivas. Nota-se que com o aumento da pressão de inflação, da mínima para a máxima, ocorreu a redução do deslocamento vertical dos pneus. Esse comportamento é condizente com Inoue et al. (1996), que observaram maiores deslocamentos do pneu agrícola em pressões de inflação consideradas baixas. Castro Neto (2001) e Dias et al. (1995) também obtiveram esses resultados para pneu agrícola.

Os cordoneís que formam as lonas do pneu agrícola são confeccionados de rayón ou nylon. Os compostos de borracha utilizados na construção da estrutura do pneu são flexíveis, sendo que o uso desses materiais faz com que o pneu agrícola tenha maior flexibilidade e elasticidade. Existe uma relação inversamente proporcional entre pressão de inflação e deslocamento vertical, ou seja, com aplicação de alta carga $(50 \mathrm{kN})$ e utilização de baixa pressão de inflação $(48,2 \mathrm{kPa})$ há um aumento do deslocamento vertical e vice-versa, como pode ser observado na Tabela 8. O ar contido na parte interna do pneu reduz a deformação das estruturas do mesmo. Segundo Barbosa e Magalhães (2015), a alta pressão interna do pneu minimiza o 
deslocamento da estrutura interna, mesmo com aplicação de alta carga sobre o mesmo, e seu diâmetro externo não se modifica.

O pneu florestal apresentou menor deslocamento vertical em todas as pressões de inflação quando comparado ao pneu agrícola, o que pode ser explicado pelo fato do fabricante recomendar alta pressão de trabalho e sua estrutura ser mais rígida devido a utilização de compostos resistentes de borracha e alguns cordoneís serem confeccionados de aço. De acordo com Cuong et al. (2014), o deslocamento vertical e a área de contato da banda de rodagem com a superfície diminuem significativamente à medida que há um aumento da pressão de inflação; segundo o autor a forma construtiva e os materiais utilizados na construção do pneu interferem nos parâmetros avaliados.

De acordo com a tabela 8, sob alta pressão de inflação os pneus agrícola e florestal obtiveram menores valores de deslocamento vertical, sendo que a redução do deslocamento dos pneus pode influenciar na redução da área de contato do pneu, causando a compactação do solo. Keller et al. (2014) avaliaram a vibração de um trator agrícola em uma pista de solo firme, em função da pressão de inflação. $O$ autor conclui que a alta pressão de inflação torna o pneu mais rígido, reduzindo sua área de contato com o solo e o deslocamento vertical e horizontal, uma vez que, essas reduções de deslocamentos do pneu proporcionam maior vibração da máquina, fato este que pode ser transferido ao operador da mesma.

O aumento da pressão de inflação do pneu florestal resultou na redução do deslocamento vertical, o que também foi observado no pneu agrícola. O maior deslocamento vertical do pneu florestal foi obtido com a pressão de inflação intermediária, sendo que a pressão de inflação intermediária é considerada baixa quando comparada com a pressão nominal e alta e quando é aplicada alta carga sobre o pneu. Na pressão de inflação mínima, a carga aplicada no pneu foi menor, o que resultou em menor deslocamento vertical quando comparada com a pressão intermediária. Este comportamento confere com Stoilov e Kostadinov (2009), que avaliaram os deslocamentos e a área de contato de um pneu florestal e concluíram que, o uso da mínima pressão de inflação combinada com a baixa aplicação de carga reduz o deslocamento do pneu.

Os resultados obtidos com o pneu florestal conferem com os resultados de Mellgren (1981), o qual observou que os pneus florestais são mais rígidos e sofrem menores 
deformações e concluiu que a variação da pressão de inflação influencia significativamente nas deformações dos pneus.

Tabela 8. Valores médios de deslocamento vertical do pneu agrícola e florestal.

\begin{tabular}{lll}
\hline Pressão de Inflação & Agrícola $(\mathrm{mm})$ & Florestal $(\mathrm{mm})$ \\
\hline Alta & $62,155 \pm 0,426 \mathrm{Da}$ & $41,667 \pm 0,516 \mathrm{Db}$ \\
Nominal & $76,61 \pm 0,707 \mathrm{Ca}$ & $46,558 \pm 0,232 \mathrm{Cb}$ \\
Intermediária & $78,875 \pm 0,538 \mathrm{Ba}$ & $55,67 \pm 1,262 \mathrm{Ab}$ \\
Mínima & $86,915 \pm 0,887 \mathrm{Aa}$ & $52,763 \pm 0,769 \mathrm{Bb}$ \\
\hline
\end{tabular}

- Em cada coluna, para cada fator, as médias seguidas de mesma letra maiúscula não diferem estatisticamente entre si, pelo teste de Tukey a $5 \%$ de probabilidade.

- Em cada linha, para cada fator, médias seguidas de mesma letra minúscula não diferem estatisticamente entre si, pelo teste de Tukey a 5\% de probabilidade.

\subsection{Deslocamento horizontal do pneu agrícola e florestal}

Os valores médios do deslocamento horizontal do pneu agrícola e florestal estão representados na Tabela 9. Quando submeteu-se os pneus agrícola e florestal à elevadas pressões de inflação, ocorreu a redução do deslocamento horizontal, o que também foi observado no deslocamento vertical. Estes comportamentos dos pneus agrícola e florestal conferem com os resultados obtidos por Taghavifar e Mardani (2013) que avaliaram as deformações e área de contato de um pneu diagonal, e verificaram que com o aumento da pressão de inflação ocorreu uma redução das deformações laterais e da área de contato e aumento da resistência ao rolamento. Segundo os autores, o deslocamento horizontal e vertical tem relação direta com área de contato.

$\mathrm{Na}$ mínima pressão de inflação não houve diferença estatística significativa entre pneu agrícola e florestal, mesmo as estruturas dos pneus sendo distintas. Isto pode ser conferido ao fato que, o uso da mínima pressão de inflação e baixa aplicação de carga no pneu florestal torna o seu deslocamento horizontal igual ao do pneu agrícola. Nas demais pressões de inflação avaliadas neste trabalho houve diferença estatística significativa entre o pneu agrícola e florestal e estes resultados conferem com o estudo elaborado por McMullan et 
al. (1988), que realizaram um ensaio comparativo entre pneu agrícola e florestal e concluíram que tipo de construção, rigidez de carcaça, pressão de inflação e a carga dinâmica influenciam no deslocamento elástico dos pneumáticos e apenas na mínima pressão de inflação o tipo construtivo e a rigidez da carcaça não influenciaram nos valores do deslocamento horizontal, o que diferiu o presente trabalho do estudo conduzido por McMullan et al. (1988).

O pneu agrícola, nas pressões intermediária e nominal e submetido à mesma carga, não apresentou diferença estatística, concluindo que o aumento da pressão de 193 kPa para 234,4 kPa não interferiu no deslocamento; outrora, o aumento da pressão de inflação nominal para alta reduziu o deslocamento horizontal. O resultado obtido é condizente com o descrito por Weissbach (2003), uma vez que o autor concluiu que o aumento da pressão de inflação, classificada nominal e alta, de $150 \mathrm{kPa}$ para $180 \mathrm{kPa}$ causou a redução de $10 \%$ no deslocamento horizontal do pneu BPAF agrícola.

De acordo com a tabela 9 pode-se notar que os pneus agrícola e florestal em algumas pressões de inflação não apresentaram diferença estatística significativa para o deslocamento horizontal. No pneu agrícola mesmo com o aumento da pressão de inflação da intermediária para nominal, a pressão de inflação não interferiu nos valores de deslocamento horizontal. O pneu florestal apresentou comportamento semelhante ao pneu agrícola na pressão nominal e alta, isso comprova que, acima de uma determinada pressão de inflação, neste caso $379,2 \mathrm{kPa}$, a pressão não influência na deformação devido às características de sua carcaça.

Tabela 9. Valores médios de deslocamento horizontal do pneu agrícola e florestal.

\begin{tabular}{lll}
\hline Pressão de Inflação & Agrícola $(\mathrm{mm})$ & Florestal $(\mathrm{mm})$ \\
\hline Alta & $3,612 \pm 0,469 \mathrm{Cb}$ & $17,697 \pm 0,0383 \mathrm{Ba}$ \\
Nominal & $7,295 \pm 0,271 \mathrm{Bb}$ & $17,907 \pm 0,319 \mathrm{Ba}$ \\
Intermediária & $7,295 \pm 0,249 \mathrm{Bb}$ & $19,452 \pm 0,312 \mathrm{Aa}$ \\
Mínima & $15,785 \pm 0,897 \mathrm{Ab}$ & $16,752 \pm 0,195 \mathrm{Cb}$
\end{tabular}

- Em cada coluna, para cada fator, as médias seguidas de mesma letra maiúscula não diferem estatisticamente entre si, pelo teste de Tukey a 5\% de probabilidade.

- Em cada linha, para cada fator, médias seguidas de mesma letra minúscula não diferem estatisticamente entre si, pelo teste de Tukey a 5\% de probabilidade. 


\section{3 Área de contato do pneu agrícola e florestal}

Na tabela 10 estão representados os valores médios da área de contato dos pneus agrícola e florestal. Pode ser observado no pneu agrícola e florestal que a redução da pressão de inflação causou o aumento da área de contato.

O resultado obtido com o pneu florestal confere com Jun et al. (2004). O autor ensaiou um pneu florestal na medida 600/55-26.5 e concluiu que a redução da pressão de inflação juntamente com a aplicação de cargas aumentou da área de contato, sendo que o autor utilizou duas pressões de inflação de 100 e 240 kPa.

No pneu agrícola o comportamento em relação área de contato está de acordo com Mazetto et al. (2004), onde o autor define que à medida que se diminui a pressão de inflação obtêm-se maiores áreas de contato para todos os pneus estudados, neste caso, o autor avaliou os pneus BPAF, radial e diagonal. Este resultado também foi obtido por Pytka et al. (2006) e Elwaleed et al. (2006). Segundo os autores, a redução da pressão de inflação em pneus agrícolas provoca o aumento da área de contato dos mesmos e a redução da pressão de inflação juntamente com aplicação de altas cargas proporciona o aumento das deformações laterais, o que ocasiona a elevação da área de contato. Diserens (2009) ressalta que o efeito da redução de pressão de inflação em aumentar a área de contato, só é garantido para altas cargas, diferindo dos resultados obtidos no presente trabalho, onde a maior área de contato do pneu agrícola foi obtida com a aplicação da mínima carga em função da mínima pressão de inflação.

Diserens et al. (2011) e Mohsenimanesh e Ward (2010) ensaiaram dois pneus, um BPAF e um radial com as mesmas dimensões. Os autores concluíram que com o aumento da pressão de inflação, ocorreu uma redução na área de contato dos pneus com o solo. Segundo estes autores, a alta pressão de inflação utilizada nos pneus causou a redução das deformações laterais, tornando o pneu mais rígido e menos flexível.

Considerando os dois pneus, agrícola e florestal, o pneu agrícola apresenta maior discrepância nos valores das áreas de contato, de acordo com as pressões de inflação utilizadas, fato que ilustra que a alteração da pressão de inflação interfere de forma significativa na área de contato do pneu agrícola. No pneu florestal, os valores da área de contato não apresentaram alta variação entre as pressões de inflação utilizadas, os intervalos entre os resultados das áreas de contato foram menores, sendo que na pressão mínima e intermediaria 
não houve diferença estatística significativa entre as duas pressões. Assim, a variação da pressão de inflação causou pouca influência na área de contato do pneu florestal, o que pode ser em detrimento das cintas de aço que envolvem a estrutura interna do pneu.

O pneu agrícola na mínima pressão de inflação apresentou a maior área de contato em relação as demais pressões de inflação utilizadas no pneu. Este comportamento do pneu agrícola também foi descrito por Corrêa (2000) que avaliou o desempenho de um trator agrícola em função da pressão de inflação dos pneus e concluiu que pressões mais baixas resultam no aumento da área de contato do pneu conferindo-lhe melhor capacidade trativa. Naranjo et al. (2014) também concordam com os resultados obtidos por Corrêa (2000), onde o autor afirma que o uso da baixa pressão de inflação proporciona aumento na força da barra de tração de um trator, pelo fato do pneu possuir uma maior área de contato com o solo.

Na Tabela 10 observa-se que para a área de contato avaliada no pneu agrícola e florestal houve diferença estatística significativa na pressão mínima, intermediária e nominal e os resultados obtidos nestas pressões de inflação mostram que a diferença de estrutura dos pneus influência nos valores médios da área de contato. Na alta pressão de inflação não houve diferença estática significava entre os dois pneus, isto pode ser explicado pelo fato do pneu agrícola, sob alta pressão de inflação, possuir uma grande quantidade de ar comprimido entre a sua parte interna e o aro.

Tabela 10. Valores médios da área de contato do pneu agrícola e florestal.

\begin{tabular}{lll}
\hline Pressão de Inflação & Agrícola $\left(\mathrm{m}^{2}\right)$ & Florestal $\left(\mathrm{m}^{2}\right)$ \\
\hline Alta & $0,128 \pm 0,096 \mathrm{Ba}$ & $0,115 \pm 0,014 \mathrm{Ba}$ \\
Nominal & $0,164 \pm 0,015 \mathrm{ABa}$ & $0,133 \pm 0,069 \mathrm{ABb}$ \\
Intermediária & $0,183 \pm 0,021 \mathrm{ABa}$ & $0,144 \pm 0,023 \mathrm{Ab}$ \\
Mínima & $0,235 \pm 0,019 \mathrm{Aa}$ & $0,131 \pm 0,016 \mathrm{ABb}$
\end{tabular}

- Em cada coluna, para cada fator, as médias seguidas de mesma letra maiúscula não diferem estatisticamente entre si, pelo teste de Tukey a 5\% de probabilidade.

- Em cada linha, para cada fator, médias seguidas de mesma letra minúscula não diferem estatisticamente entre si, pelo teste de Tukey a 5\% de probabilidade. 
Esta grande quantidade de ar presente internamente no pneu torna-o mais rígido e menos flexível, assim a estrutura do pneu agrícola se torna muito semelhante a estrutura do pneu florestal.

Não houve diferença estatística entre pressão intermediária e nominal para a área de contato do pneu agrícola, sendo que a carga aplicada no pneu foi igual para as duas pressões de inflação, e o aumento da pressão de $193 \mathrm{kPa}$ para 234,4 kPa, ou seja, o aumento de 8 \%, não causou interferência na área de contato. 


\section{CONCLUSÕES}

Com o aumento da pressão de inflação, da mínima para alta, ocorreu a redução do deslocamento horizontal e vertical e redução da área de contato para os dois tipos de pneu avaliados. A estrutura do pneu influenciou na variação das pressões, sendo o pneu agrícola mais sensível a estas variações.

O pneu agrícola apresentou maior deslocamento vertical em relação ao pneu florestal, em detrimento de suas estruturas.

A rigidez do pneu florestal não permitiu que, a elevação da pressão de inflação da nominal para a alta pudesse ocasionar uma alteração no deslocamento horizontal, ou seja, determinados valores de pressão não interferem sobre o deslocamento. No pneu agrícola, os valores do deslocamento horizontal foram iguais nas pressões intermediária e nominal, significando que, nesta faixa de pressão o pneu agrícola não sofre alteração em decorrência do aumento da pressão.

O uso da alta pressão de inflação nos pneus agrícola e florestal não alterou a área de contato em ambos, mesmo havendo diferenças estruturais entre eles, por sua vez, nas demais pressões os pneus diferiram entre si. 


\section{REFERÊNCIAS}

ANTIQUEFARMING, Disponível em: <http: www.antiquefarming.com>. Acesso em: 10 fev. 2015.

ALLIS-CHALMERS, Disponível em: <http://www.allischalmerslawn.com/about_us/>. Acesso em 25 abr. 2015.

ASSOCIAÇÃO LATINO AMERICANA DOS FABRICANTES DE PNEUS, AROS E RODAS. Manual de normas técnicas. São Paulo, 2013. 40p.

ASSOCIAÇÃO LATINO AMERICANA DOS FABRICANTES DE PNEUS, AROS E RODAS. Manual de normas técnicas. São Paulo, 2013. 61p.

ASSOCIAÇÃO NACIONAL DA INDÚSTRIA DE PNEUMÁTICOS. Produção da indústria Brasileira de pneus em 2015. São Paulo, 2015. 20p.

BAILEY, A. C.; RAPER, R. L.; WAY, T. R. et al. Soil stresses under a tractor tire at various loads and inflation pressures. Journal of Terramechanics, v.33, n.1, p.1-11, 1996. 
BARBOSA, L. A. P. Compactação do solo gerada por pneus de alta flutuação de eixo livre e trativo. 2012. 104f. Dissertação (Mestrado em Engenharia Mestrado em Engenharia Agrícola/Máquinas Agrícolas) - Faculdade de Engenharia Agrícola, Universidade Estadual de Campinas, Campinas, 2012.

BARBOSA, L. A. P., MAGALHÃES, P. S. G. Tire tread pattern design trigger on stress distribution over rigid surfaces and soil compaction. Journal of Terramechanics, v. 58, p. $27-38,2015$

BORGHI, G. Análise dos pneus florestais. Curitiba. Universidade Federal do Paraná. 2012. Disponível em: http://www.colheitademadeira.com.br/informativos/298/estudo-tecnicoestrutural-150;-analise-dos-pneus-florestais.html. Acesso em: 18 ago. 2013.

CAMBI, M.; CERTINI, G.; NERI, F.; MARCHI, E. The impact of heavy traffic on forest soils: A review. Forest Ecology and Management, v. 338, p. 124-138, 2014.

CASTRO NETO P. Desenvolvimento e avaliação de equipamentos e metodologia para determinação de parâmetros físicos do solo relacionados a dias trabalháveis com máquinas agrícolas. 2001. 155f. Tese (Doutorado em Agronomia/Energia na Agricultura) Faculdade de Ciências Agronômicas, Universidade Estadual Paulista, Botucatu, 2001.

CONTINENTAL. Fact Book. 2015. 37p.

CORRÊA, I. M. Conheça o pneu agrícola que você usa. Revista Unesp Rural, Jaboticabal, v. 18 , p. $21,1999$.

CORREAA, I. M. Desempenho operacional de pneus radias e diagonais em função da pressão de inflação, da condição de superfície do solo e da condição de acionamento da tração dianteira. 2000. 121f. Tese (Doutorado em Agronomia/Energia na Agricultura) Faculdade de Ciências Agronômicas, Universidade Estadual Paulista, Botucatu, 2000. 
CUETO, O. G.; CORONEL, C. E. I.; MORFA, C. A. R.; SOSA, G. U.; GÓMEZ, L. H. H.; CALDERÓN, G. U.; SUÁREZ M. H. Three dimensional finite element model of soil compaction caused by agricultural tire traffic. Computers and Electronics in Agriculture, v. 99, p. 146-152, 2013.

CUONG, D. M.; ZHU, S.; ZHU, Y. Effects of tyre inflation pressure and forward speed on of na unsuspended tractor. Journal of Terramechanics, v. 50, p. 185-198, 2013.

CUONG, D. M.; ZHU, S.; NGOC, N. T. Study on the variation characteristics of vertical equivalent damping ratio of tire-soil system using semi-empirical model. Journal of Terramechanics, v. 51, p. 67-80, 2014.

DIAS, G.P.; LIMA, J.S.S.; FREITAS, M.C. et al. Constantes elásticas de pneus de tratores agrícolas como função de pressão de enchimento e da altura de garras. In: CONGRESSO BRASILEIRO DE ENGENHARIA AGRÍCOLA, 24., 1995, Viçosa. Resumos... Viçosa: SBEA, 1995. p.331.

DISERENS, E.; DÉFOSSEZ, P.; DUBOISSET, A.; ALAOUI, A. Prediction of the contact area of agricultural traction tyres on firm. Biosystems Engineering, v. 110, p. 73-82, 2011.

DISERENS, E. Calculating the contact area of trailer tyres in the field. Soil \& Tillage Research, v. 103, p. 302-309, 2009.

EUROPEAN TYRE AND RUBBER MANUFACTURERS ASSOCIANTION. Statistics edition 2014. 12p.

ELWALEED, A. K.; YAHYA, A.; ZOHADIE, M.; AHMAD, D.; KHEIRALLA, A. F. Effect of inflation pressure on motion resistence ratio of a high-lug agricultural tyre. Journal of terramechanics, v. 43, p. 69-84, 2006.

FERNANDES, H.C. Máquinas de exploração florestal: compactação das trilhas e dias 
potencialmente úteis para o trabalho. Botucatu, 1996. 145f. Tese (Doutorado em Agronomia /Energia na Agricultura) - Faculdade de Ciências Agronômicas, Universidade Estadual Paulista, Botucatu, 1996.

FERNANDES, H. C.; LOPES, S. E.; LEITE, D. M.; MILAGRES, R. S.; SANTOS, L. N. Compactação do solo em função do tráfego de máquinas florestais. Revista Agrotecnologia, Anápolis, v. 4, n. 2, p. 85-98, 2013.

FIRESTONE, The Firestone legacy. Disponivel em:

$<$ http://www.firestonetire.com/about/heritage>. Acesso em: 03 abr. 2015.

GABRIEL FILHO, A.; MONTEIRO, L. A.; GUERRA, S. P. S.; JESUÍNO, P. R. Influência da altura das garras dos pneus de um trator em área de plantio direto. Engenharia Agrícola e Ambiental. Campina Grande, v. 14, n. 10,1123-1128, 2010.

GREACEN, E. L.; SANDS, R. Compaction of forest soils a review. Gleis Osmond: Australian Journal of Soil Research v. 18, n. 2, p. 163-89, 1980.

GRECENKO, A.; PRIKNER, P. Tire rating based on soil compaction capacity. Journal of Terramechanics, v. 58, p. 77-92, 2014.

GOODYEAR, The Charles Goodyear story. Disponivel em: <http://www.goodyear.com/coporate/history_story.html>. Acesso em: 02 abr. 2015.

HORN, R.; VOSSBRINK, J.; BECKER, S. Modern forestry vehicles and their impacts on soil physical properties. Soil \& tillage research, v. 79, p.207-219, 2004.

INOUE, G.H.; DIAS, G. P.; QUEIROZ, D.M. et al. Efeito da pressão de enchimento e desgastes das garras e frisos na elasticidade lateral de pneus de tratores agrícolas. In: CONGRESSO INTERNACIONAL DE INGENIERIA RURAL, 2., 1996, Neuquen. Memorias... Neuquen: INTA, 1996. p.142-146. 
JESUÍNO, P. R. Desempenho de um trator agrícola em função do desgaste das garras dos pneus e das condições superficiais do solo. 2007. 76f. Dissertação (Mestrado em Agronomia/Energia na Agricultura) -Faculdade de Ciências Agronômicas, Universidade Estadual Paulista, Botucatu, 2007.

JUN, H. G.; WAY, T. R.; LOFGREN, B.; LANDSTROM, L.; BAILEY, A. C.; BURT, E. C. MCDONALD, T. P. Dynamic load and inflation pressure effects on contact pressures of a forestry forwarder tire. Journal of Terramechanics, v. 41, p. 209-222, 2004.

KELLER, T., BERLI, M.; RUIZ, S.; LAMANDÉ, M.; ARVIDSSON, J.; SHOJONNING, P.; SELVADURAI, A. P. S. Transmission of vertical soil stress under agricultural tyres: comparing measurements with simulations. Soil \& Tillage Research. V. 140, p. 106-117, 2014.

KIM, K.U.; REHKUGLER, G. E. A review of tractor dynamics and stability. Trans. ASAE (Am.Soc.Agric.Eng.), v.30, p.615-623, 1987.

\section{LAGUË, C.; AGNEW, J.; KHELIFI, M. Theoretical evaluation on the feasibility of controlled traffic farming using wide-span implements carriers for Canadian agriculture. In: ANNUAL MEETING OF THE CSAE/SCGR, 2003, p. 03-233, 2003.}

LYASKO, M.I. The determination of deflection and contact characteristics of a pneumatic tire on a rigid surface. Journal of Terramechanics, v.31, n.4, p.239-246, 1994.

LIER, Q. J. V.; Física do solo. 1. ed. Viçosa: SBCS, 2010. 298 p.

LOPES, A.; LANÇAS, K. P, FURLANI, C. E. A.; NAGAOKA, A. K.; CASTRO NETO, P., GROTTA, D. C. C.. Consumo de combustível de um trator em função do tipo de pneu, da lastragem e da velocidade de trabalho. Engenharia Agrícola e Ambiental. Campina Grande. v. 7, n. 2, p. 382-386, 2003. 
LOPES, A.; LANÇAS, K. P.; SILVA, R. P. Desempenho de um trator em função do tipo de pneu, da lastragem e da velocidade de trabalho. Ciência Rural, Santa Maria, RS, v. 35, n. 2, p. 366-370, 2005.

MAZETTO, F.R; LANÇAS, K.P. Determinação da área de contato de pneus agrícolas utilizando uma prensa hidráulica estática. In: CONGRESSO DE INICIAÇÃO CIENTÍFICA, 12., 2000, São José do Rio Preto, Resumos... São José do Rio Preto: Universidade Estadual Paulista, 2000. p.260.

MAZETTO, F. R. Avaliação das metodologias de determinação das áreas de contato e deformações elásticas de pneus agrícolas em função das pressões de inflação e cargas radiais. 2004. 96f. Dissertação (Mestrado em Agronomia/Energia na Agricultura) - Faculdade de Ciências Agronômicas, Universidade Estadual Paulista, Botucatu, 2004.

MAZETTO, F. R.; LANÇAS, K. L.; NAGAOKA, A. K.; CASTRO NETO, P.; GUERRA, S. P. S. Avaliação do contato pneu-solo em três modelos de pneus agrícolas. Engenharia Agrícola, Jaboticabal, SP, v. 24, n. 3, p. 750-757, 2004.

MÁRQUEZ, L. Tractores agrícolas: Tecnología y utilizacion. 1. Ed. Madrid: B\&H Editores, 2011.843 p.

MÁRQUEZ, L. Especial pneus agrícolas. Agri World, Madrid, ESP, n. 1, p 2-6, out. / nov. 2010 .

MCMULLAN, T. A. G.; PLACKETT, C. W.; PEACHEY, R. The behavior of tractor drive tyres at low inflation pressures when reacting side force. J. Agric. Res., v.39, p.221-229, 1988.

MELLGREN, P. G. Trials on muskeg with high flotation forestry tires. In: Proceedings of the 7th International Conference of the International Society for Terrain-Vehicle Systems, Calgary (Alberta, Canada), v. 2, p. 737-753, 1981. 
MICHELIN, The Michelin Company. Disponivel em:

$<$ http://www.michelin.com/corporate/EN/group/history $>$. Acesso em: 17 fev. 2015.

MITAS Agricultural Tires, Technical Databook $13{ }^{\mathrm{TH}}$ Edition. Czech Republic. 2013. 15p.

MOHSENIMANESH, A.; WARD, S. M. Estimation of a three-dimensional tyre footprint using dynamic soil-tyre contact pressures. Journal of Terramechanics, v. 47, p. 415-421, 2010.

NARANJO, S. D.; SANDU, C.; TAHERI, S. Experimental testing of the off-road instrumented tire on soft soil. Journal of Terramechanics, v. 56, p. 119-137, 2014. NOKIAN TIRES. Heavy tyres technical manual. Forestry Tyres. 2013. 22p.

PAULA, C. A. D. Desenvolvimento de um perfilômetro laser para determinação da área e volume de contato entre o pneu e o solo. 2008. 83f. Dissertação (Mestrado em Agronomia/Energia na Agricultura) - Faculdade de Ciências Agronômicas, Universidade Estadual Paulista, Botucatu, 2008.

PYTKA, J.; DABROWSKI, J.; ZAJAC, M.; TARKOWSKI, P. Effects of reduced inflation pressure and vehicle loading on off-road traction and soil stress and deformation state. Journal of terramechanics, v. 43, p. 469-485, 2006.

PORTERFIELD, J. W.; CARPENTER, T. G. Soil compaction: an index of potential compaction for agricultural tires. Trans. ASAE, St. Joseph, v.29, n.4, p.917-22, 1986.

UPADHYAYA, S.K.; WULFSOHN, D. Review of traction prediction equations. In: ASAE (Am.Soc.Agric.Eng.), 1990, St. Joseph. (Paper 90-1573)

YANAI, K.; SILVEIRA, G.M.; LANÇAS, K.P.; CORRÊA. I.M.; MAZIERO, J.V.G. Desempenho operacional de trator com e sem acionamento da tração dianteira auxiliar.Pesquisa Agropecuária. Brasileira, Brasília, v.34, n.8, p.1427-34, 1999. 
SANTOS, P. I. B. Método dos elementos finitos para determinação da área de contato, entre um rodado e uma superfície deformável. 2003. 203f. Tese (Doutorado em Agronomia/Energia na Agricultura) - Faculdade de Ciências Agronômicas, Universidade Estadual Paulista, Botucatu, 2003.

SAKAI, H.; NORDFJELL, T.; SUADICANI, K.; TALBOT, B.; BOLLEHUUS, E. Soil compaction on forest soils from diferente kinds of tires and tracks and possibility of accurate estimate. Croat. Journal, v. 29, p. 15-27, 2008.

SERRANO, J. M. P. R. Pressão de insuflagem dos pneus no desempenho do conjunto tratorgrade de discos. Pesquisa Agropecuária Brasileira. Brasília, DF, v. 43, n. 2, p. 227-233, 2008.

SILVEIRA, G. M. Os cuidados com o trator. 1. Ed. Viçosa: Aprenda fácil editora, 2001. 312 p.

SPAGNOLO, R. T.; VOLPATO, C. E. S.; BARBOSA, J. A.; PALMA, M. A. Z.; BARROS, M. M. Fuel consumption of a tractor in function of wear, of ballasting and tire inflation pressure. Engenharia Agrícola. Jaboticabal, SP, v. 32, n. 2, p. 131-139, 2012.

STOILOV, S.; KOSTADINOV, G. D. Effect of weight distribution on the slip efficiency of a four wheel drive skidder. Biosystems Engineering, v.04, p. 486-492, 2009.

TAGHAVIFAR, H.; MARDANI, A. Investigating the effect of velocity, inflation pressure, and vertical load on rolling resistance of a radial ply tire. Journal of Terramechanics, v. 50, p. 99-106, 2013.

TRELLEBORG. Agricultural tyres manual. 2013. 49p. 
WEISSBACH, M. On-the-move monitoring of soil-tyre interaction on soft soil using wireless data acquisitio. Soil Cutting and Tillage. v. 4, n. 3, p. 8-16, 2003. 